\title{
Transcription Factors in Cartilage Homeostasis and Osteoarthritis
}

\author{
Margot Neefjes, Arjan P. M. van Caam $®$ and Peter M. van der Kraan * \\ Experimental Rheumatology, Radboud University Medical Centre, Geert Grooteplein 28, 6525 GA Nijmegen, \\ The Netherlands; margot.neefjes@radboudumc.nl (M.N.); arjan.vancaam@radboudumc.nl (A.P.M.v.C.) \\ * Correspondence: peter.vanderkraan@radboudumc.nl; Tel.: +31-24-16568
}

Received: 27 July 2020; Accepted: 7 September 2020; Published: 14 September 2020

\begin{abstract}
Osteoarthritis (OA) is the most common degenerative joint disease, and it is characterized by articular cartilage loss. In part, OA is caused by aberrant anabolic and catabolic activities of the chondrocyte, the only cell type present in cartilage. These chondrocyte activities depend on the intraand extracellular signals that the cell receives and integrates into gene expression. The key proteins for this integration are transcription factors. A large number of transcription factors exist, and a better understanding of the transcription factors activated by the various signaling pathways active during OA can help us to better understand the complex etiology of OA. In addition, establishing such a profile can help to stratify patients in different subtypes, which can be a very useful approach towards personalized therapy. In this review, we discuss crucial transcription factors for extracellular matrix metabolism, chondrocyte hypertrophy, chondrocyte senescence, and autophagy in chondrocytes. In addition, we discuss how insight into these factors can be used for treatment purposes.
\end{abstract}

Keywords: osteoarthritis; cartilage; transcription factors; gene expression analysis; transcriptome; transcriptional regulation

\section{Introduction}

Osteoarthritis $(\mathrm{OA})$ is the most common degenerative joint disease, and it is characterized by progressive articular cartilage loss, osteophyte formation, and subchondral bone remodeling. In addition, $\mathrm{OA}$ is often accompanied by synovial inflammation. Ultimately, OA can cause disability, which greatly and negatively impacts the quality of life of patients [1]. Treatment options for OA are very limited as there are, to date, no disease-modifying drugs available [2].

Articular cartilage is the connective tissue covering the end of bones in articular joints. This tissue is of crucial importance in facilitating smooth and frictionless movement and acts as a shock absorber upon movement. It is a special type of tissue as it is non innervated and does not contain blood vessels for the supply of oxygen and nutrients [3,4]. In addition, there is only one highly specialized cell type present, i.e., the chondrocyte $[3,5]$. Chondrocytes are essential for constructing, maintaining, and repairing the extracellular matrix (ECM) [6], which makes up for $98 \%$ of articular cartilage [5], and they do so by balancing the production of major matrix components, like collagen type II (COL2A1) and aggrecan (ACAN), with that of ECM-degrading enzymes, such as matrix metalloproteinases (MMPs) and a disintegrin and metalloproteinase with thrombospondin motif (ADAMTSs). Aberrant chondrocyte function contributes to $\mathrm{OA}$, and numerous homeostatic processes are disturbed in OA, including matrix maintenance and autophagy. Aberrant chondrocyte function can be caused by an altered phenotype; in OA, amongst others, both a hypertrophy-like phenotype, in which the cells resemble hypertrophic chondrocytes in the growth plate, and a senescence-associated secretory phenotype (SASP), in which chondrocytes produce various proinflammatory cytokines, can be observed $[7,8]$. 
Ultimately, this change in chondrocyte function and phenotype observed during $\mathrm{OA}$ is due to the intra- and extracellular signals that the chondrocyte receives and integrates into gene expression over time. The integration of these different signals runs via modulation of transcription factor (TF) activity, the key proteins that regulate gene expression. A disrupted amount or activity of TFs is the cause of various diseases, including cancer [9,10], developmental disorders [11], cardiovascular disease [12], and autoimmune diseases such as systemic lupus erythematosus [13,14]. In this review, we will explore the role of TFs in OA (development) by addressing how the most important ones regulate ECM metabolism, chondrocyte hypertrophy, chondrocyte senescence, and autophagy on a transcriptional level. Furthermore, the potential of the transcription factor profile to help stratify patients into different subtypes and the value of this for personalized medicine and treatment options will be discussed.

\section{Transcription Factors}

TFs are DNA-binding proteins that regulate gene transcription $[15,16]$. This makes them key cellular components that determine how a cell reacts to both intra- and extracellular signals by converting these signals into gene expression, and, ultimately, TFs control crucial biological processes such as cell cycle progression, maintenance of metabolic balance, and cellular differentiation $[17,18]$. Many TFs are present in the human genome; estimations range from 500 to 2600 TFs $[15,19,20]$. Various types of TFs exist. To begin, there are those that are obligatory for any gene expression, such as transcription factor II A and transcription factor II B, because they are part of the transcription initiation complex [21]. Then, there are those TFs that determine cellular lineage, the so-called master regulators (MRs) [22], which control the expression of hundreds of lineage-specific genes. These MRs typically work by regulating histone-modifying enzymes to control the epigenetic state of chromatin and regulate enhancer and promoter activity to ensure a gene expression profile fitting for the cell type [23]. An example of such an MR is myoblast determination protein (MYOD), which by itself can drive mesenchymal cells to differentiate into myoblasts [24]. The genes that are made accessible by these MRs are subject to regulation by the third class of TFs, the classical transcription factors that bind to the promoter or any other regulatory element and (directly) regulate target gene transcription.

To function, TFs need to bind DNA. For this, TFs recognize highly conserved unique sequences of nucleotides of approximately 6 to 12 base pairs long [25]. Such TF binding sites can be located close to the transcription start site (TSS), but there are also so-called cis-regulatory elements that can be located hundreds and even thousands of base pairs from the TSS, such as insulators, enhancers, and silencers [25]. There are various mechanisms how TF function can be modulated to correctly coordinate specific gene expression, which is fundamental to cellular function (Figure 1). First, TF function can greatly depend on the interaction with other TFs or cofactors (factors that regulate transcription but do not have DNA-binding capacity) [26]. For example, whether distally located regulatory elements interact (or not) with the proximal promoter can depend on looping mechanisms that can only occur through certain cofactor binding (Figure 1A) [27]. Furthermore, the binding affinity of TFs to DNA can be subject to modulation by recruitment of other factors, e.g., low-affinity can change into high-affinity via cofactor binding [28]. For example, recombinant RelA dimers bind to nuclear factor kappa B (NFKB) DNA sites; however, when another TF such as p53 is added, RelA DNA binding affinity increases up to 4-fold [29]. If a TF binds DNA, this does not necessarily result in gene expression; this can be threshold-dependent, i.e., binding of low levels of TF does not induce gene expression, but binding of TFs above a certain threshold concentration activates gene expression, creating a switch-like effect (Figure 1B). For example, in T-lymphocytes, the TF nuclear factor of activated T-cells (NFAT) only induces the expression of its target genes above a threshold concentration [30]. Alternatively, an additive model is also possible where activation is proportional to the concentration of the $\mathrm{TF}$, as was shown for $\mathrm{NFKB}$, where an increased concentration led to a proportionally increased gene transcription [31]. Another key aspect that strongly regulates TF activity is combinatorial occupancy. This mechanism depends on the interaction of TFs with other 
TFs or cofactors to alter their function. Thereby, the same TF can induce different responses based on its interaction partners (Figure 1C). For example, SMAD family member 3 (SMAD3), a downstream TF of transforming growth factor $\beta$ (TGF $\beta$ ) signaling, has many cell-type-specific effects due to interacting with different cofactors in different cell types, such as octamer-binding transcription factor 4 in embryonic stem cells and MYOD1 in myotubes [32]. Another regulatory mechanism of TF activity is post-translational protein modification (Figure 1D). Post-translational modifications can affect nuclear entry, protein-protein interactions, and protein turnover. For example, (de)phosphorylation is an important modification, i.e., the phosphorylation of the NFkB family member RelA at position Ser536 results in the interaction with the cofactor p300, enhancing the transcriptional activity, whereas lack of this phosphorylation prevents this interaction [33]. Last, chromatin accessibility also greatly affects TF function (Figure 1E). Heterochromatin, a very compact nucleosome structure, is almost not accessible for TFs, whereas euchromatin, which has a less dense structure, facilities TF binding. The conformation of chromatin is mainly determined by the histone modifications present. These different mechanisms that determine TF function are extensively reviewed in [26].

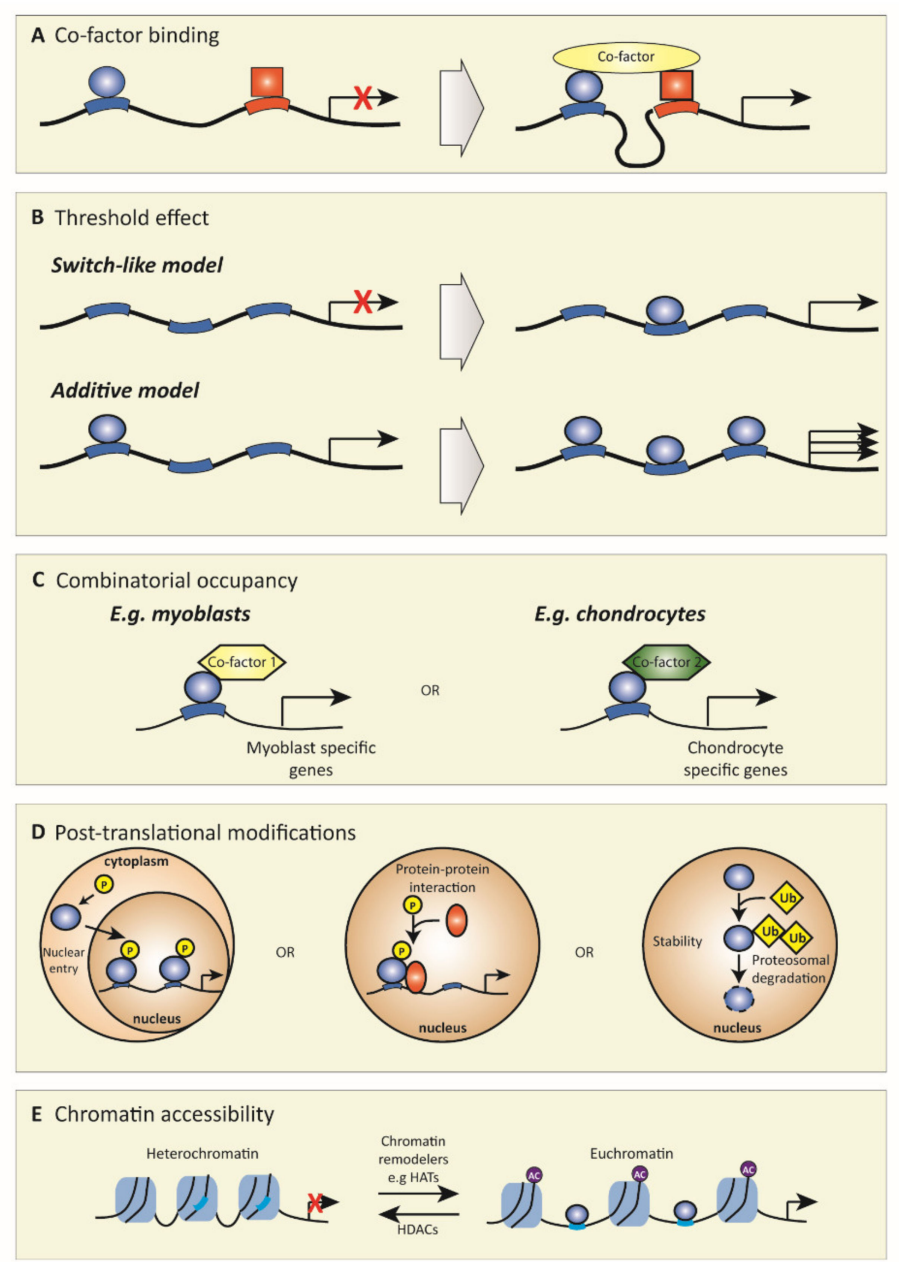

Figure 1. A schematic depiction of different mechanisms of transcription factor function. Models of how transcription factors can affect transcription by (A) cofactor binding, (B) threshold effect, (C) combinatorial occupancy, (D) post-translation modifications, and (E) chromatin accessibility. (A) Some transcription factors need cofactors to activate transcription. For example, cofactor binding can create a looping of the DNA, which brings transcription factors that are normally far apart into close proximity, which results in activated transcription. (B) For some genes, transcription is an on/off switch where, in the absence of transcription factors, no transcription occurs, while above a certain concentration binding of transcription factors results in transcription (switch-like model). For other genes, binding of more transcription factors 
results in higher gene expression (additive model). (C) The same transcription factor can induce different responses based on its interaction partners (combinatorial occupancy). For example, in myoblasts, transcription factor 1 interacts with cofactor 1 to express myoblast specific genes, while in chondrocytes, this same transcription factor interacts with cofactor 2 to express chondrocyte specific genes. (D) Posttranslational modification is very important for the function of transcription factors, e.g., they can cause nuclear entry of transcription factors that are otherwise rendered in the cytoplasm or they can affect protein-protein interactions, and they have an important role in protein stability and turnover. (E) Chromatin accessibility determines if transcription factor binding sites are available for transcription factors to bind. Heterochromatin, a very dense nucleosome structure, is not accessible for transcription factors to bind, whereas euchromatin, a less dense nucleosome structure, is available for transcription factor binding. HATs = histone acetyl transferases; HDACs = histone deacetylases.

\section{Transcription Factors in OA}

The importance of a well-regulated TF network is demonstrated by the fact that errors in these mechanisms or mutations in TF binding sites result in various diseases, such as cancer and autoimmunity $[10,13]$. Now we will discuss the role of a selection of TFs in cartilage and OA (development). A key TF for chondrocyte phenotype and activity is SRY-BOX transcription factor 9 (SOX9) asthis TF is the MR of chondrogenesis and regulates different phases of chondrocyte development, e.g., by stimulating early mesenchymal condensation and proliferation and inhibiting chondrocyte hypertrophy and chondrocyte senescence [34-36]. The importance of SOX9 for cartilage development has been established both in vitro and in vivo. For example, the embryonic stem cells of Sox9-knockout mice cannot form cartilage [34], and inactivation of Sox 9 via the Cre/LoxP system in mouse embryos before mesenchymal condensation results in a complete absence of cartilage formation [37]. Furthermore, in humans, haploinsufficiency of SOX9 results in a lethal skeletal malformation syndrome called campomelic dysplasia [38]. In human OA chondrocytes, SOX9 expression is reduced compared to healthy chondrocytes [35,39,40]. Possibly, this loss of SOX9 as MR relates to the altered chromatin landscape observed in OA. A recent study using ATAC-sequencing (a technique to assess genome-wide chromatin accessibility) identified that the genome of OA chromosomes was more accessible for transcription at 1565 places and less accessible at 2885 places compared to healthy cartilage [41]. This included enhancer regions regulating important genes such as SOX9, SOX11, and many other genes involved in mesenchymal fate commitment, regulators of ossification, and chondrocyte differentiation. Furthermore, enrichment analysis of TF-binding motifs in the differentially accessible regions identified binding sites for TFs such as activator protein 1 (AP-1), CCAAT-enhancer-binding protein (C/EBP), erythroblast transformation specific (ETS), and signal transducer and activator of transcription 3 (STAT3), suggesting that these TFs might be important in regulating altered gene expression in OA. In addition, a transcriptome study reported differential expression of $93 \mathrm{TFs}$ (out of a total of 865) in human knee OA cartilage compared to normal cartilage [42]. These $93 \mathrm{TFs}$ included JUN, EGR1, JUND, FOSL2, MYC, KLF4, RelA, and FOS. Another study also identified JUN, JUND, MYC, and FOS as the four TFs that are central in regulating signaling pathways in OA knee cartilage [43].

Altered post-translational modifications may also play a role in OA [44]. TFs such as AP-1, SMAD3/4, hypoxia-inducible factor (HIF), and C/EBP are targets of post-translational modifications [45]. The importance of post-translational modifications, for example, phosphorylation in $\mathrm{OA}$, is demonstrated by inhibition of p38 mitogen-activated protein kinase (MAPK), a kinase that can phosphorylate TFs in pellets from articular cartilage chondrocytes, which resulted in decreased glycosaminoglycan deposition and increased expression of hypertrophy markers [46]. Furthermore, inhibition of the p38 MAPK pathway resulted in suppressed apoptosis and decreased expression of proinflammatory cytokines in human OA chondrocytes [47]. Interestingly, increased activation of p38 MAPK was detected in human OA cartilage versus control cartilage [48]. Inflammation is also shown to influence these kinases and phosphatases in chondrocytes, suggesting that under inflammatory conditions, post-translational modification of transcription factors might be altered [49]. Altogether, these studies emphasize the crucial role of TFs in OA development, and we will now discuss the role of TFs in four crucial processes of OA: ECM metabolism, hypertrophy, SASP, and autophagy. 


\subsection{Transcription Factors Related to ECM Metabolism}

In healthy cartilage, chondrocytes maintain the ECM by synthesizing and remodeling its components. Chondrocytes do this by balancing the production of ECM molecules with that of ECM-degrading molecules. Two major ECM protein components of articular cartilage are COL2A1 and ACAN [3], while key proteins in cartilage ECM degradation are members of the MMP and ADAMTS families. Both families consist of multiple members (19 ADAMTSs [50] and 23 MMPs members in humans [51]), but MMP3, MMP13, ADAMTS4, and ADAMTS5 are the most important ones in cartilage [52]. In OA, the balance in matrix production and degradation is disturbed, leading to loss of ECM, which is one of the main hallmarks of OA. This disturbed balance can be the result of decreased ECM deposition, increased ECM degradation, or both (Figure 2). However, in early OA, chondrocytes produce more ECM proteins, as measured by increased mRNA expression and enhanced incorporation of ${ }^{35} \mathrm{~S}$-radiolabeled cysteine or methionine and sulfate in proteins and proteoglycans, respectively, in early experimental OA models [53,54], making the first option unlikely in the early stages of OA development. This makes it more likely that loss of ECM is a consequence of excessive ECM degradation caused by elevated expression of ECM-degrading enzymes such as MMPs and ADAMTSs. In healthy chondrocytes, these enzymes are expressed at a low level, which is (in part) regulated by epigenetic modifications that silence their expression, for example, via DNA methylation at CpG sites, which prevent TFs from binding to DNA [55,56]. High levels of such methylation are present in healthy chondrocytes at the promoters of MMP3, MMP13, and ADAMTS4, but in OA chondrocytes, many of these $\mathrm{CpG}$ sites are unmethylated, making these genes more accessible for transcription [55]. For example, Bui et al. demonstrated that in human OA cartilage, the amount of demethylation of the MMP13 promotor positively correlates with increased MMP13 expression [57]. Furthermore, ADAMTS4 promotor demethylation was also shown in human OA knee cartilage, together with increased expression of ADAMTS4 [58], suggesting that the loss of CpG methylation could lead to enhanced expression of ADAMTS4. It is not exactly clear what triggers the demethylation of these promoters, but age, changes in ion concentrations, and inflammatory cytokines are implicated in this process $[57,59,60]$. These factors can affect DNA methylation either by a passive mechanism, where DNA methylation is inhibited by binding of TFs during cell division, or via an active mechanism by activating DNA methyltransferases to remove methyl groups [61]. Together, these studies show that the chromatin state is crucial in determining the level of expression of genes, and, in OA, this chromatin state is altered, leading to dysregulated expression of MMPs and ADAMTSs.

After opening up the chromatin, the promoter region of MMPs and ADAMTSs is accessible for TFs to regulate their expression. Key TFs for MMP3 and MMP13 regulation include AP-1, runt-related transcription factor 2 (RUNX2), NFkB, HIF2 $\alpha$, and T-cell factor/lymphoid enhancer factor (TCF/LEF) [62-64], whereas ADAMTS4 and ADAMTS5 expression strongly respond to NFAT, RUNX2, SOX4, SOX11, and NFKB $[65,66]$. In OA, multiples of these TFs are differently expressed. For example, expression of $A P-1$, which is a dimeric TF primarily composed of FOS and JUN proteins, has been shown to be increased in knee OA cartilage [42,43]. Inhibition of AP-1 activity in vitro by the use of the small molecule inhibitor T-5224 inhibited MMP3 and MMP13 production in SW1353 chondrocytes [67]. In vivo, the use of T-5224 in the destabilization of the medial meniscus (DMM) experimental $\mathrm{OA}$ mouse model inhibited the progression of cartilage degeneration by inhibiting MMP13 expression [68]. Besides AP-1, SOX4 and SOX11 mRNA levels are also increased in human OA cartilage compared to nonosteoarthritic cartilage [66,69]. Overexpression of SOX4 or SOX11 in mouse cartilage resulted in enhanced cartilage destruction, with increased ADAMTS5 and MMP13 expression [66]. However, both SOX4 and SOX11 have not been extensively studied in $\mathrm{OA}$, and no deletion or inhibition studies have been performed to investigate the potential therapeutic effect hereof. NFkB, also a dimer TF, can be composed of five different subunits- $\mathrm{NF \kappa B} 1$ (p105/p50), NFкB2 (p100/p52), RelA (p65) RelB, and c-Rel—and also regulates ECM-degrading enzyme expression [70]. For example, knockdown of p65 in a rat model of OA (resecting medial collateral ligament and the medial meniscus model) via intra-articular small interfering RNA (siRNA) delivery 
resulted in decreased degradation of cartilage compared to the vehicle-treated group [71]. Furthermore, I $\kappa B$ kinases (IKK) are important for the function of the NFKB family as these kinases regulate the release of $\mathrm{NFKB}$ from inhibitory-binding proteins in the cytoplasm, resulting in translocation to the nucleus and activation. In vitro, selective inhibition of IKK by BMS-345541 resulted in decreased expression of interleukin (IL)1 $\beta$-induced expression of MMP13 and ADAMTS5 in human articular chondrocytes [72]. Furthermore, the administration of the IKK inhibitor in a surgically-induced OA mouse model (resecting medial collateral ligament and the medial meniscus model) resulted in significantly less cartilage destruction compared to the vehicle control group, indicating that TFs of the NFKB family regulate cartilage degradation. TFC/LEF TFs are also implicated in regulating matrix-degrading enzymes. Of the four family members (TCF1, TCF3, TCF4, and LEF1), TCF4 is most abundantly present and elevated in human OA cartilage compared with healthy cartilage [73]. Overexpression of TCF4 in human chondrocytes induced the expression of $M M P 1, M M P 3$, and $M M P 13$, whereas knockdown of TCF4 resulted in decreased MMP1 and MMP13 mRNA levels and had no effect on MMP3 levels. TCF/LEF TFs are mainly activated by Wnt signaling, and a small molecule Wnt inhibitor that inhibits TCF/LEF activity (SM04690) has been shown to alleviate cartilage destruction in an OA rat model by decreased expression of Mmp1, Mmp3, Mmp13, and Adamts5 [74]. A clinical phase 1 study with the same small molecule inhibitor resulted in a positive effect on OA pain and function [75].

As mentioned, in the initial stage of $\mathrm{OA}$, chondrocytes show increased production of ACAN and COL2A1 [76]. Both ACAN and COL2A1 are regulated by the so-called SOX trio (i.e., SOX5, SOX6, and SOX9) [77]. In human knee articular cartilage of early OA patients, increased expression of COL2A1 and ACAN was observed, together with increased SOX9 expression, while the loss of SOX9 at later stages of OA was correlated with the loss of both COL2A1 and ACAN expression [78]. Besides SOX9, SOX6 was also downregulated in damaged knee OA cartilage compared to undamaged cartilage [69,79]. A correlation analysis study demonstrated strong correlations between loss of TFs SOX5 and SOX9 and decreased expression of COL2A1 in knee OA chondrocytes, whereas loss of SOX6 was highly correlated with less $A C A N$ expression [80]. Together, these studies suggest that the levels of the SOX trio play a crucial role in COL2A1 and ACAN expression.

The function of SOX9 is not only dependent on its expression levels but also on its post-translational modifications. For example, it was shown that phosphorylation of SOX9 by cAMP-dependent protein kinase A (PKA) increased activity of a COL2A1 promoter reporter by more efficient DNA binding of this TF in fibroblastic COS7 cells [81]. Thus, (increased) phosphorylation of SOX9 could explain the enhanced expression of COL2A1 and ACAN in the early stages of OA; however, whether this happens in OA chondrocytes is not known. Another post-translational modification that affects SOX9 function is (de)acetylation. In human chondrocytes, the histone deacetylase (HDAC) sirtuin 1 (SIRT1) has been shown to bind to SOX9 and affect the acetylation status of SOX9. SIRT1 activity results in the recruitment of different cofactors such as PGC-1 $\alpha$, p300, and GCN5 to SOX9, and this has been linked to increased COL2A1 expression [82]. In human OA chondrocytes, elevated SIRT1 protein expression was measured [83], and overexpression of SIRT1 results in increased COL2A1 expression [84]. However, Fujita et al. demonstrated that SIRT1 expression levels decrease with the progression of human OA [85]. Besides (de)phosphorylation and (de)acetylation, SOX9 can also be ubiquitylated, which causes protein degradation. The ubiquitin ligase E6-AP is known to be able to ubiquitinate SOX9 in chondrocytes, and it was demonstrated that E6-AP deficient mice have elevated levels of SOX9 in their chondrocytes [86]; however, whether these mice are protected against OA development due to elevated levels of SOX9 has not been investigated yet. Furthermore, expression analysis of E6-AP and SOX9 revealed that SOX9 was present in resting, proliferating, and prehypertrophic chondrocytes, but was absent in hypertrophic chondrocytes, whereas the E6-AP was highly expressed in hypertrophic chondrocytes but absent from prehypertrophic chondrocytes [86]. Together, these studies indicate that altered post-translational modification may lead to aberrant SOX9 function in OA chondrocytes. 


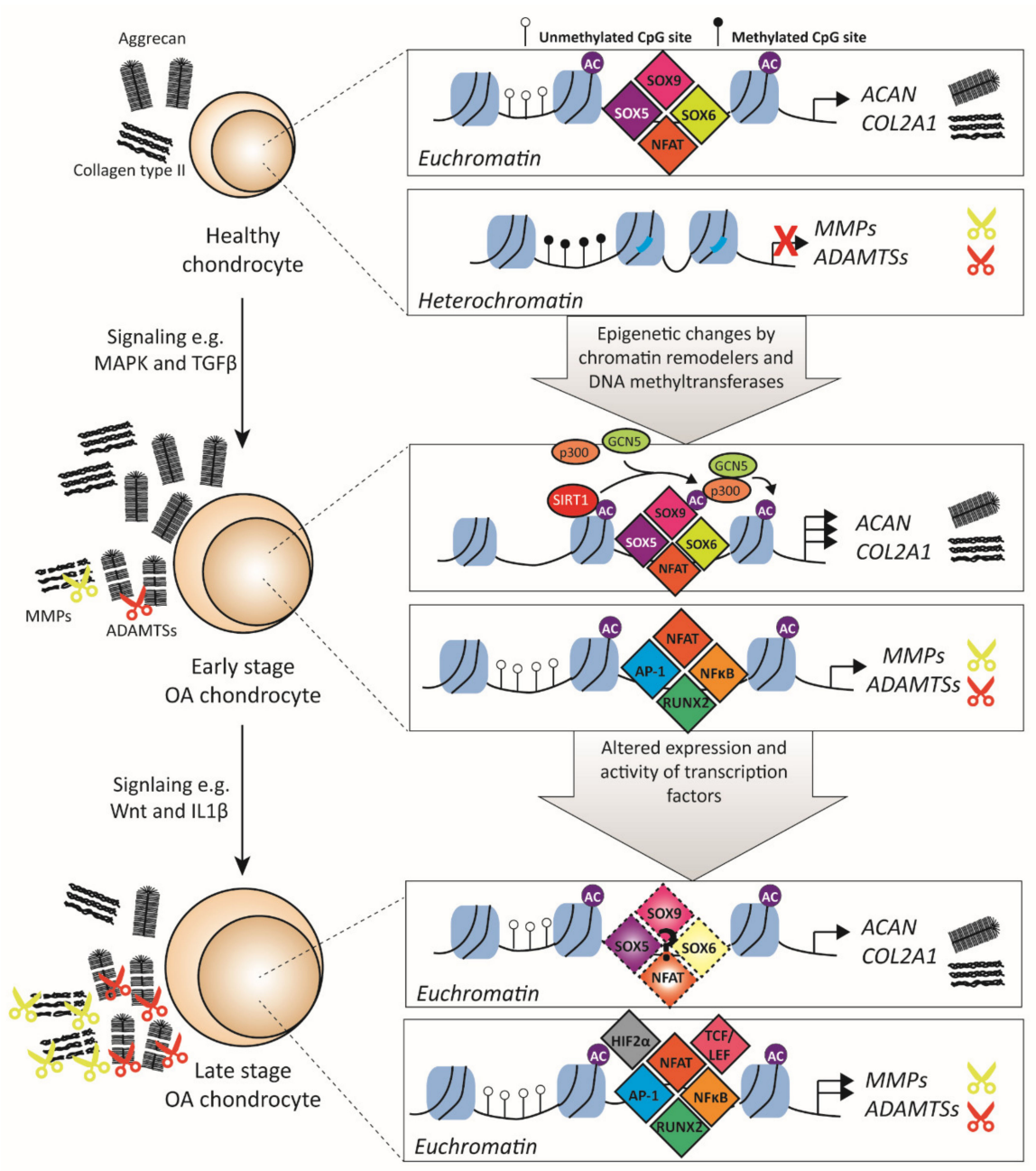

Figure 2. Transcription factors involved in extracellular matrix (ECM) metabolism. Model of how transcription factors are involved in the regulation of ECM production and degradation. Healthy chondrocytes synthesize ECM proteins such as ACAN and COL2A1. Important transcription factors for these genes are SOX5, SOX6, SOX9, and NFAT. In addition, in a healthy chondrocyte, matrix-degrading enzymes, such as MMPs and ADAMTSs, are expressed at a low level or not at all. These genes are silenced by epigenetic modifications. During osteoarthritis (OA), epigenetic changes occur by chromatin remodelers, resulting in either a conformation to euchromatin or heterochromatin, depending on the gene. In early OA, chondrocytes increase the production of important ECM proteins. One of the proposed mechanisms for this increase is the enhanced activation of transcription factors such as SOX9. SIRT1 can acetylate SOX9, which results in the recruitment of HAT cofactors such as p300 and GCN5, which, in turn, hyperacetylate surrounding histones. At this stage, transcription factors are recruited to the promoter regions of the ECM-degrading enzyme genes, such as AP-1, RUNX2, NFAT, and NFkB, and transcription takes place. In late OA chondrocytes, transcription levels of ECM-degrading enzymes increase, together with a loss of ECM production, as there are altered expression and function of transcription factors that are important for both these processes. Furthermore, epigenetic changes also occur, and, together, this results in the silencing of the ECM genes. $\mathrm{MMP}=$ matrix metalloproteinase; ADAMTS $=$ a disintegrin and metalloproteinase with thrombospondin motif; $\mathrm{AP}-1$ = activator protein 1; RUNX2 = runt-related transcription factor 2; NFAT = nuclear factor of activated T-cells; HAT = histone acetyltransferase; $\mathrm{NF} \kappa \mathrm{B}=$ nuclear factor kappa $\mathrm{B}$; ACAN = aggrecan; COL2A1 = collagen type II; SOX5 = SRY-BOX transcription factor 5; SOX6 = SRY-BOX transcription factor 6; SOX9 = SRY-BOX transcription factor 9; HIF2 $\alpha=$ hypoxia-inducible factor 2-alpha; TCF/LEF = T-cell factor/lymphoid enhancer factor. 
Besides the SOX trio, other TFs such as NFAT, paired box (PAX), SMAD3, specificity protein 1 (SP1), and glioma-associated oncogene (GLI) are also important for the transcriptional regulation of cartilage ECM proteins [77,87-89]. Loss (or gain) of these factors might cause impaired expression of ACAN and COL2A1. For example, articular chondrocytes of Nfat $1 \mathrm{KO}$ mice showed a reduction of Acan and Col2a1 expression compared to articular chondrocytes of WT mice [90]. Forced expression of NFAT1 in these cells resulted in the rescue of Acan and Col2a1 expression. Additionally, family members of the SP family are involved in COL2A1 expression, such as SP1 and SP3, but these factors have opposite roles. It was shown that in rabbit articular chondrocytes, SP1 can activate Col2a1 expression, whereas, in the presence of SP3, this activation is lost [89]. Furthermore, it was shown that the ratio of SP3/SP1 is altered during dedifferentiation of chondrocytes, with a pronounced loss of SP1 [91]. This increased SP3/SP1 ratio can be partly attributed to the effect of proinflammatory cytokines, as in rabbit articular chondrocytes it was shown that IL1 $\beta$ inhibited Col2a1 expression by increasing the SP3/SP1 ratio [92], indicating that this disturbed ratio may also play a role in decreased COL2A1 expression in OA, as proinflammatory cytokines are present in OA. The growth factor TGF $\beta$, which signals via the SMAD TFs, induces the expression of COL2A1 and ACAN [93]. The knockdown of SMAD3 or SMAD4 during chondrogenesis in bone-marrow-derived mesenchymal stem cell pellets resulted in inhibition of both COL2A1 and ACAN expression [94]. In both aging and OA cartilage, SMAD3 expression is decreased [95]. Furthermore, another TGF $\beta$ family member, bone morphogenetic protein (BMP), signals via the TF complex SMAD1/5/9. Chondrocyte-specific knockdown of both SMAD1 and SMAD5 in mice resulted in a reduction of COL2A1 deposition, while ACAN protein levels were not altered [96]. In conclusion, both ECM production, as well as ECM degradation, is altered in OA by altered TF expression and function.

\subsection{Transcription Factors Related to Hypertrophy}

During OA, chondrocytes can become hypertrophic and undergo terminal differentiation [97]. Healthy chondrocytes express proteins such as Indian Hedgehog (IHH) and parathyroid hormone-like protein (PTHrP) that regulate hypertrophic differentiation via a negative feedback loop. When signaling by these factors is altered, chondrocytes become hypertrophic, obtain an increased cell size, and switch to a new genetic program, with the expression of new proteins like collagen type X (COL10A1) and MMP13 (Figure 3) [98]. In addition, hypertrophic chondrocytes actively mineralize their surroundings with protein-like alkaline phosphatase (ALPL). Multiple signaling pathways are involved in obtaining the hypertrophy-like phenotype, such as active thyroid hormone (T3), Wnt, MAP-kinases, Notch, and TGF $\beta$ signaling [98]. It is thought that before marked cartilage degradation, human chondrocytes change their morphology and volume, which are linked to the phenotypic stability of the chondrocyte [99]. The observed increased cell size at the early stages of hypertrophic differentiation is such an example. Cell size is a tightly regulated cell characteristic, and, in chondrocytes, it has been demonstrated that many factors are associated with the morphological changes that happen during hypertrophy. It is thought that reduced osmolarity in OA cartilage is one of the main causes for the increase in cell size [100]. In OA, it is shown that the transcription of ion channels is changed [101,102]. For example, acid-sensing potassium channel (TASK-2), epithelial sodium channel $(E N a C)$, and $\mathrm{Ca}^{2+}$ activated chloride channel (TMEM16) transcription is decreased, while expression of $\mathrm{Ca}^{2+}$ activated potassium channels (KCa3.1 and KCa1.1) increase in OA [103]. However, not much is known about which TFs regulate this aberrant expression in chondrocytes. Altered transcription of ion channels results in changes in intracellular ion concentrations, leading to an increase in cell volume. Furthermore, changes in intracellular ion concentrations can lead to the release of intracellular messengers that, in turn, can activate or repress post-translational modification enzymes [104]. These enzymes can affect the function of TFs by modulating their post-transcriptional modification sites. For example, the activation of the TF NFAT is dependent on dephosphorylation by the calcium-dependent phosphatase calcineurin [105]. In addition, other TFs are also dependent on intracellular ion concentrations, such as NFKB and CREB [106]. However, not much is known about the role of this in the terminal differentiation of chondrocytes. 


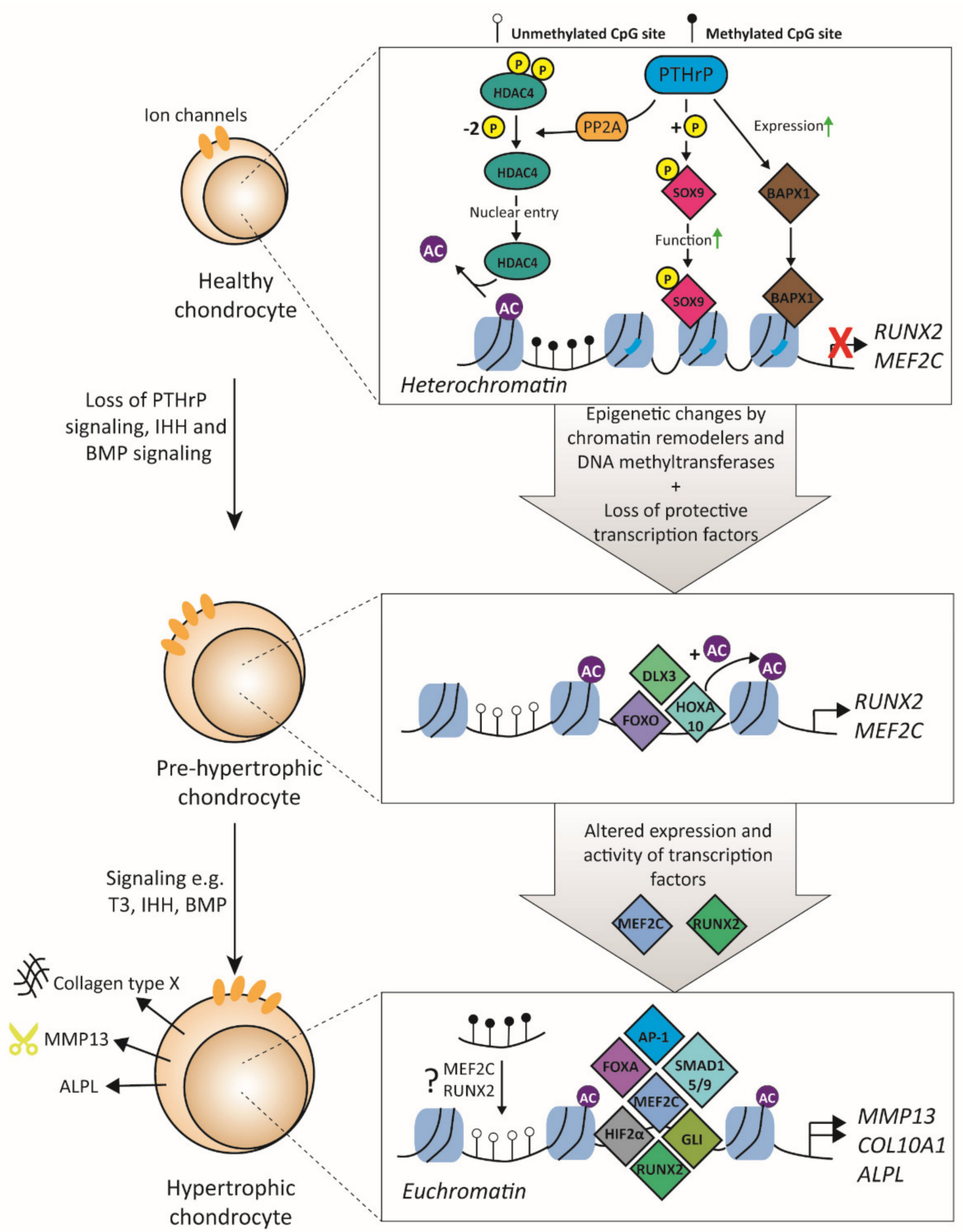

Figure 3. Transcription factors involved in chondrocyte hypertrophy. In a healthy chondrocyte, hypertrophy-related genes are silenced due to the compact composition of the nucleosomes and transcription factors that repress hypertrophy. PTHrP is a crucial signaling molecule that represses chondrocyte hypertrophy by increasing expression of BAPX-1, increasing SOX9 activity, and inducing nuclear translocation of HDAC4 to maintain hypoacetylation of the promoters of RUNX2 and MEF2C. In prehypertrophic chondrocytes, epigenetic changes occur by, e.g., loss of chromatin remodelers and loss of protective transcription factors against hypertrophy. This leads to increased chondrocyte volume and the opening of chromatin. TFs such as HOXA10, FOXO1, and DLX3 can bind in the promoter of RUNX2 and activate its transcription. RUNX2 and MEF2C are the MR of chondrocyte hypertrophy and regulate, in turn, with other transcription factors, the expression of hypertrophy makers such as COL10A1, MMP13, and ALPL. PTHrP = parathyroid hormone-like protein; SOX9 = SRY-BOX transcription factor 9; BAPX-1 = homeobox protein Nkx-3.2; HDAC4 = histone deacetylase 4; $\mathrm{NF} \kappa \mathrm{B}=$ nuclear factor kappa $\mathrm{B} ; \mathrm{RUNX} 2$ = runt-related transcription factor 2; MEF2C = myocyte-specific enhancer factor $2 \mathrm{C}$; AP-1 = activator protein $1 ; \mathrm{GLI}=$ glioma-associated oncogene; FOXA = forkhead box transcription factor class A; HIF2 $\alpha$ = hypoxia-inducible factor 2-alpha; COL10A1 = collagen type X; MMP13 = matrix metalloproteinase 13; ALPL = alkaline phosphatase. 
Moreover, the gained expression of hypertrophy markers COL10A1 and MMP13 depends, firstly, on chromatin remodeling to euchromatin and, secondly, on the activation of their promoter. The remodeling of chromatin mostly depends on HDACs. HDAC4 is guided by PTHrP signaling; PTHrP causes decreased phosphorylation of HDAC4 by protein phosphatase 2 (PP2A), which results in translocation to the nucleus, where it can act as a repressor of the TFs myocyte-specific enhancer factor 2C (MEF2C) and RUNX2 [107]. Both MEF2C and RUNX2 are TFs that are crucial for chondrocyte hypertrophy. Forced expression of RUNX2 induced hypertrophy in nonhypertrophic chondrocytes [108], and, similarly, expression of a superactive form of MEF2C in mice led to increased chondrocyte hypertrophy, whereas deletion of MEF2C in COL2A1-expressing chondrocytes in mice resulted in the absence of chondrocyte hypertrophy [109]. Of note, MEF2C is thought to be an upstream player of RUNX2. Importantly, it has been shown that HDAC4 and MEF2C have opposing roles in regulating chondrocyte hypertrophy and that the balance of these TFs is important in regulating this process. For example, the deletion of one Mef2c allele in Hdac4 $\mathrm{KO}$ mice normalized ossification of the cartilage, while deletion of one Hdac4 allele in Mef2c knockdown mice restored ossification [109]. Interestingly, HDAC4 levels decrease with age and are even further decreased in OA cartilage [110], and such loss of HDAC4 can, thus, possibly result in more RUNX2 and MEF2C activity. In contrast, increased expression of RUNX2 is observed in OA cartilage [40], but it is not known whether MEF2C expression is altered in human OA cartilage. HDAC4 represses $M E F 2 C$ and RUNX2 transcription by a closed DNA conformation; however, when HDAC4 expression is lost during OA, DNA structure transforms from heterochromatin to euchromatin, and TFs can bind to activate transcription of MEF2C and RUNX2. HOXA10 is such a TF that binds the RUNX2 promoter. In osteoblasts, it was shown that HOXA10 recruits histone acetyltransferases (HATs) to the RUNX2 promoter, resulting in hyperacetylation [111]. Another TF that is important in RUNX2 transcriptional regulation is DLX3; it was demonstrated that overexpression of DLX3 in RUNX2 null cells resulted in induced RUNX2 expression [112]. Other TFs that play a role in RUNX2 expression are forkhead box transcription factor class O (FOXO) 1, DLX5, and SATB2 [113]; however, not much is known about which TFs regulate $M E F 2 C$ expression in chondrocytes. In addition to HDACs, the methylation state of a gene is also important for either gene silencing or activation. A methylome study revealed that MMP13 was hypomethylated in hip OA cartilage compared to control cartilage [114]. Furthermore, it has been shown that an OA-risk single nucleotide polymorphism correlated with a differently methylated region that altered expression of RUNX2 [115]. Together, this indicates that the epigenetic state of chromatin is an important determinant of hypertrophic gene expression.

Besides the ability of PTHrP to repress prohypertrophic TFs, it can also activate (or induce) antihypertrophic TFs such as SOX9 and homeobox protein Nkx-3.2 (BAPX-1). That SOX9 is important in repressing chondrocyte hypertrophy is shown in mice with a heterozygous Sox 9 deletion, which demonstrates increased maturation of immature chondrocytes into hypertrophic chondrocytes [116]. In COS7 cells, it was shown that PTHrP can increase SOX9 phosphorylation and thereby increase its transcriptional activity [117]. Another TF that inhibits chondrocyte hypertrophy is BAPX-1, as knockdown of BAPX-1 in human articular chondrocytes resulted in a hypertrophic phenotype shift that could be rescued by overexpression of BAPX-1 [118]. Inhibition of hypertrophy by BAPX-1 is, at least partially, related to the repression of RUNX2 and COL10A1 expression as BAPX-1 knockdown in mouse chondrocytes resulted in decreased expression of these two genes [119]. BAPX-1 expression is induced by PTHrP, as BAPX-1 expression was lost in Pthrp knockout mice, whereas stimulation of chick hypertrophic chondrocytes with PTHrP resulted in upregulation of BAPX-1 expression [120]. Another TF family that inhibits chondrocyte hypertrophy by repressing transcription of the hypertrophy markers is the SP family. The SP3/SP1 ratio is important for the regulation of gene expression, as is shown, for example, for COL2A1 [89]. SP1 inhibits the expression of COL10A1, as was shown by overexpressing SP1 together with a COL10A1 promoter reporter construct in hypertrophic cells [121]. However, in hypertrophic chondrocytes, this inhibition is lost as the SP3/SP1 ratio is higher than in nonhypertrophic chondrocytes, mainly because SP1 expression is much higher in nonhypertrophic versus hypertrophic chondrocytes [121]. 
After chromatin remodeling, various TFs can bind and regulate the expression of the hypertrophy markers COL10A1 and MMP13. Important TFs for both genes are SMAD1/5/8, RUNX2, AP-1, NFAT, forkhead box transcription factor class A (FOXA), and HIF2 $\alpha[122,123]$. The importance of SMAD1/5/8 has been demonstrated by inhibition of this complex, which resulted in decreased IHH-induced mineralization by primary chondrocytes [124]. Furthermore, knockout studies have shown that both SMAD1 and SMAD5 are essential for endochondral bone formation, which relies on terminal differentiation of chondrocytes [96], indicating that they may also play a role in hypertrophy in OA. In addition, inhibition of SMAD1/5/8 by dorsomorphin after initial chondrogenic differentiation of bone-marrow-derived mesenchymal stem cells led to decreased expression of COL10A1, MMP13, and ALPL and completely blocked mineralization of the matrix [125]. In osteoblast differentiation, it was demonstrated that SMAD1/5/8 indirectly activates RUNX2 expression by increasing $A P-1$ expression (JUNB), and stimulation of JUNB-overexpressing C2C12 cells with BMP2 resulted in higher ALPL activity than C2C12 cells without overexpressed JUNB [126]. Additionally, in mice hypertrophic chondrocytes, AP-1 family members such as Jun and Fosl2 are important as overexpression of these AP-1 family members results in higher Col10a1 expression [127]. More importantly, JUN and FOSL2 are highly expressed in early mice hypertrophic chondrocytes [127]. Similarly, HIF $2 \alpha$ has been shown to be crucial in inducing hypertrophy as overexpression of Hif $2 \alpha$ in ATDC 5 cells demonstrated increased expression of Col10a1, Mmp13, and ALPL activity [122]. Interestingly, HIF2 $\alpha$ expression is increased in both mice and human OA cartilage, and HIF $2 \alpha$ deficiency in mice protects against OA development in the DMM mouse model $[122,128]$. It has been demonstrated that HIF2 $\alpha$ is a downstream target of the prohypertrophic T3 signaling molecule in cartilage tissue [129], explaining the induction of hypertrophy markers COL10A1, MMP13, and ALPL by T3 [130]. In addition to HIF2 $\alpha$, FOXA has been demonstrated to be involved in chondrocyte hypertrophy. In chicken chondrocytes, overexpression of Foxa2 resulted in increased BMP2-induced expression of Col10a1, Mmp13, Vegf, and $\mathrm{Alpl}$, whereas ablation of Foxa 2 by short hairpin RNA decreased expression of these hypertrophy markers [131]. In the DMM murine OA model, expression of FOX2A was increased in OA cartilage compared to healthy cartilage, and chondrocyte-specific deletion of Foxa2 in the DMM model resulted in decreased cartilage breakdown [132]. In conclusion, these results provide evidence that chondrocyte hypertrophy is regulated by many different signaling pathways; however, the TFs MEF2C and RUNX2 can be considered the MRs of chondrocyte hypertrophy and, therefore, might be interesting therapeutic targets.

\subsection{Transcription Factors Related to Cellular Senescence}

Cellular senescence is defined by stable cell cycle arrest while the cell remains metabolically active [133]. Cellular senescence is characterized by altered morphology, chromatin structure, and gene expression pattern. $\mathrm{Xu}$ et al. demonstrated a role for cellular senescence in OA by injection of senescent fibroblasts in the knee joints of mice, resulting in an OA-like disease state with cartilage erosion [134]. In OA, senescent chondrocytes secrete a variety of proinflammatory cytokines, chemokines, proteases, and growth factors, and this is known as SASP. Furthermore, the expression of several proteins important in cell cycle arrest is increased in senescent cells such as p16 and p21. The mechanism of how cells go into senescence and start secreting SASP is not completely understood; however, both DNA damage and activation of p38 MAPK are thought to be crucial (Figure 4) [135]. It has been shown that DNA damage plays a role in acquiring the senescent phenotype in OA chondrocytes [136], and it is suggested that the DNA damage observed in OA chondrocytes results in a change of gene transcription activity. This might be explained by the observation that the binding capacity of TFs to damaged DNA is altered, as was experimentally shown for AP-1, NFKB, and SP1 TFs [137]. 


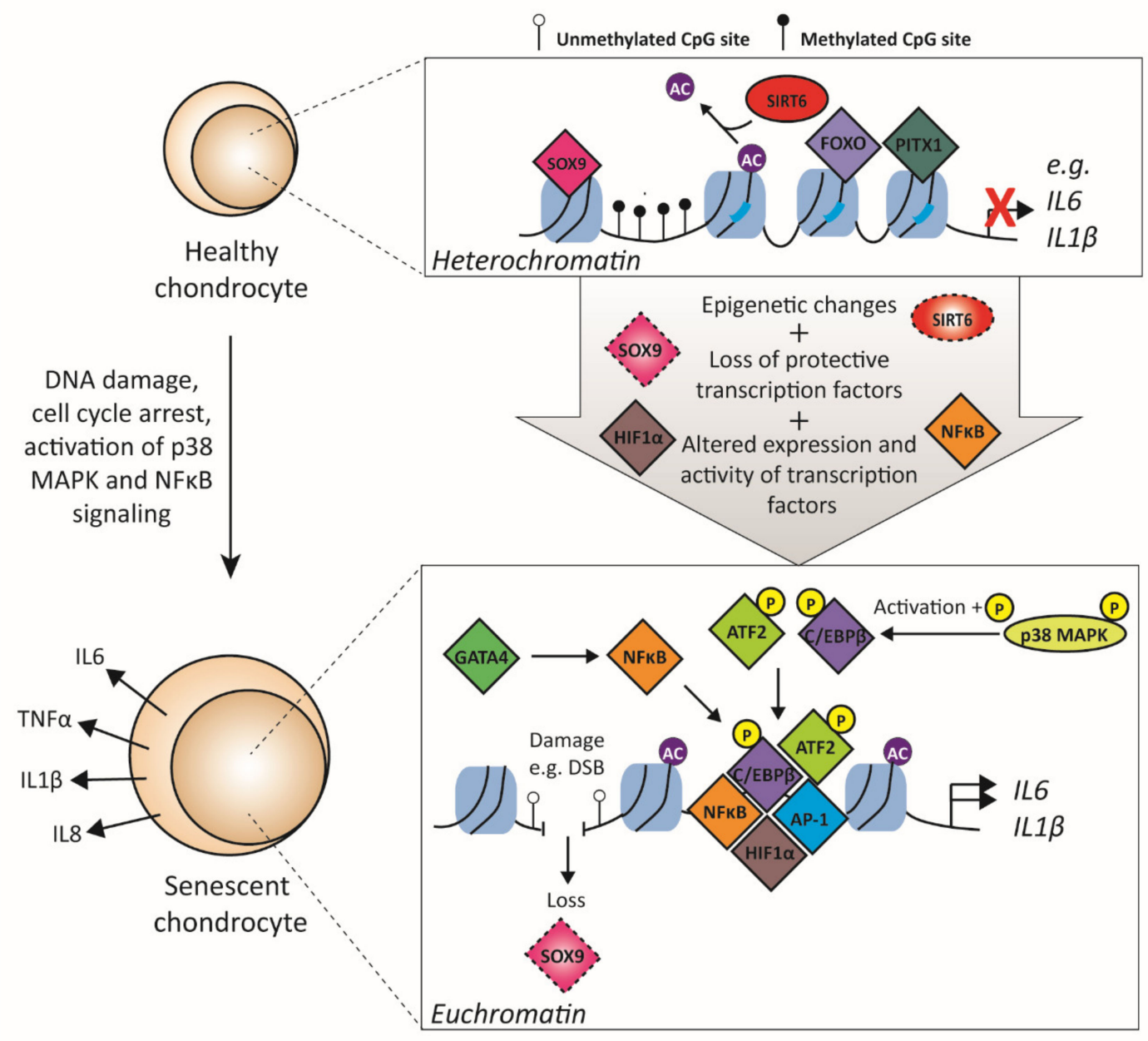

Figure 4. Transcription factors involved in senescence-associated secretory phenotype (SASP). In a healthy chondrocyte, senescence-related genes are silenced due to the compact composition of the nucleosomes and transcription factors that repress senescence, such as SOX9, FOXO, and PITX1. In OA development, multiple events occur, such as DNA damage, resulting in disrupted transcription factor binding. Furthermore, cells undergo cell cycle arrest, and different signaling pathways are activated. Together, this results in epigenetic changes by, e.g., loss of chromatin remodelers and loss of protective transcription factors. After the opening of chromatin, transcription factors can bind to promoter regions of SASP genes, and this results in increased transcription of these genes. In addition, the expression of these transcription factors is enhanced in OA cartilage, and their function can be enhanced by, e.g., post- translation modification by p38 MAPK. SOX9 = SRY-BOX transcription factor 9; FOXO = forkhead box transcription factor class O; PITX1 = paired-like homeodomain 1; SIRT6 = sirtuin 6; DBS = double-strand break; MAPK = mitogen-activated protein kinase; HIF1 $\alpha=$ hypoxia-inducible factor 1-alpha; $\mathrm{NFkB}=$ nuclear factor kappa B; AP-1 = activator protein $1 ; \mathrm{c} / \mathrm{EBP} \beta=\mathrm{CCAAT}-$ enhancer-binding protein beta; $\mathrm{ATF} 2=$ activating transcription factor 2; IL6 = interleukin 6; IL8 = interleukin 8; IL1 $\beta=$ interleukin 1 beta; TNF $\alpha=$ tumor necrosis factor alpha.

The main proinflammatory cytokines that are thought to be associated with OA development are tumor necrosis factor alpha $(\mathrm{TNF} \alpha)$ and IL1 $\beta$ as these cytokines can stimulate the expression of a range of other proinflammatory cytokines and proteases, such as IL6, IL8, and MMPs [138]. Therefore, TNF $\alpha$ and IL1 $\beta$ are now recognized as senescence inducers. The induction of SASP is accompanied by various epigenetic changes. However, SIRT6, a deacetylase, is an important protein inhibiting cellular senescence as depletion of SIRT6 in human chondrocytes results in the induction of cellular senescence [139]. Interestingly, SIRT6 protein levels are decreased in knee articular cartilage of OA 
patients compared to healthy cartilage [140]. In HeLa cells, SIRT6 interacts with the NFkB family member RelA and deacetylates $\mathrm{H} 3 \mathrm{~K} 9$ on promoters of $\mathrm{NF} \kappa \mathrm{B}$ targets genes, resulting in a more closed chromatin conformation and, therefore, decreases the accessibility of NFKB to bind to the respective promoters and activate transcription [141]. In human chondrocytes, Wu et al. demonstrated that SIRT6 protects against cellular senescence by suppressing NFKB transcriptional activity [140], suggesting that the mechanisms of deacetylating H3K9 may also occur in chondrocytes. Besides chromatin remodelers such as SIRT6, there are also TFs associated with the repression of cellular senescence and SASP. For example, SOX9 and SMAD2/3 are TFs that are known to inhibit cellular senescence by maintaining the expression of the main ECM proteins [36]. Besides these, FOXO TFs have also been shown to have a protective role by regulating inflammation and DNA repair. FOXO transcription factors are downstream targets of MAPK signaling, and phosphorylation of FOXO TFs results in its inactivation by inhibiting nuclear entry [142]. Both IL1 $\beta$ and TNF $\alpha$ increase phosphorylation of FOXO TFs and thus inhibit their activity and reduce their expression in cultured chondrocytes [143]. Furthermore, in human knee OA cartilage, higher phosphorylation of FOXO was observed compared with normal cartilage. Besides FOXO, other TFs (also the TF paired-like homeodomain 1 (PITX1)) are involved in inhibiting senescence. Inhibition of PITX1 in nonaffected OA chondrocytes by siRNA resulted in enhanced senescence as the expression of p21, p53, and collagen type I was enhanced, while overexpression of PITX1 resulted in decreased senescence [144]. Interestingly, PITX1 expression is lower in affected knee OA cartilage versus nonaffected knee OA cartilage [144], indicating that the protective effect of PITX1 against cellular senescence is possibly lost in OA.

An important activator of senescence is possibly GATA binding factor 4 (GATA4). In lung fibroblasts, it is shown that the TF GATA4 is crucial in cellular senescence, as ablation of GATA4 by siRNA results in decreased cellular senescence and SASP [145]. GATA4 acts upstream of NFkB as RelA suppression decreases GATA4-induced SASP. However, not much is known about GATA4 expression in chondrocytes. MicroRNA-204 is an important upregulated factor in senescent chondrocytes, and it has been shown to be induced by GATA4 and NFkB [146], suggesting that GATA4 may also play a role in chondrocytes. Furthermore, GATA4 expression increases in multiple tissues, such as the liver and kidneys, during aging in mice, but whether this also occurs in cartilage is not known [145]. However, because OA is an age-related disease, there is a possible link. Other TFs important in regulating the expression of proinflammatory cytokines and thus supporting a SASP phenotype are AP-1, HIF1 $\alpha$, C/EBP $\beta$, cAMP response element-binding protein (CREB), and SP1 [147]. The importance of HIF1 $\alpha$ has been demonstrated; the overexpression of HIF1 $\alpha$ increases IL1B promoter activity in human chondrocytes. [148]. In addition, HIF1 $\alpha$ expression is reported in OA chondrocytes and OA cartilage [149]. In cancer, it has been demonstrated that the TF C/EBP $\beta$, together with NFKB, is of major importance in the induction of SASP [150]. C/EBP $\beta$ has an autoinhibited form; however, post-translational modifications (e.g., phosphorylation) can induce a conformational change that results in the activation of $\mathrm{C} / \mathrm{EBP} \beta$. In cancer, the activated RAF kinase induces such post-translational modifications and activates C/EBP $\beta$ to induce SASP production. In the chondrogenic ATDC 5 cells, it was shown that overexpression of C/ebpb, together with Gadd45b, resulted in increased activation of senescent marker $p 21$. Furthermore, C/EBP $\beta$ expression was found in senescent chondrocytes [151], suggesting that this TF might also play in role in SASP in chondrocytes. However, whether this switch to the activated form also occurs due to post-translational modifications of $C / E B P \beta$ in chondrocytes is not known. C/EBP $\beta$ is a known target of p38 MAPK, an important kinase crucial in cellular senescence that is activated during chondrocyte senescence, suggesting that induced post-translational modifications of C/EBP $\beta$ might also cause the switch to an activated TF. Additionally, other TFs important in regulating SASP inflammatory mediators, such as members of the AP-1 TF family and activating transcription factor 2 (ATF2), are subject to post-translational modifications by p38 MAPK [44]. Inhibition of p38 with the small molecule inhibitor SB203580 in rabbit articular chondrocytes resulted in a delay in senescence onset, measured by decreased senescence-associated $\beta$-galactosidase activity [152]. Furthermore, it has been shown that activated (i.e., phosphorylated) p38 levels are higher in senescent chondrocytes 
and that this induced the phosphorylation of ATF2, whereas this does not happen in freshly isolated chondrocytes, which have low levels of activated p38. Inactivation of p38 with a dominant-negative form resulted in both a reduction of senescence-associated $\beta$-galactosidase activity and inhibition of ATF2 phosphorylation, suggesting that the delayed onset of chondrocyte senescence is associated with post-translational modifications of ATF2. The exact mechanisms of how p38 inhibition results in decreased cellular senescence is not known, but as TFs are a main target of p38, it could occur via altered post-translational modifications of TFs.

\subsection{Transcription Factors Related to Autophagy}

Macroautophagy (often referred to as autophagy) is a mechanism in which damaged cellular constituents such as organelles and proteins are recycled via lysosomal degradation in order to maintain cellular metabolism [153]. In this process, the cell encapsulates its own components, e.g., mitochondria, in a membrane (the autophagosome), which then merges with a lysosome to recycle the components (all steps in the autophagy process and related proteins are extensively reviewed in [154]). This mechanism is induced in response to different kinds of stressors, such as nutrient starvation, hypoxia, invading organisms, and oxidative stress [155]. Activation of autophagy is a rapid process that mainly depends on post-translational protein modifications and protein-protein interactions. However, in the last decade, it became clear that especially protracted autophagic responses are mediated by a change in the transcriptional program of autophagy-related (ATG) genes [156]. Autophagy is thought to be cytoprotective and it has been suggested to be a negative regulator of inflammasome activation by degradation of inflammasome components [157-159]. The inflammasome regulates the immune response by maturation of proinflammatory cytokines such as IL1 $\beta$ and this process also contributes to OA development as inflammasome activation is enhanced in OA [160]. Autophagy activity decreases with age [161] and also plays an important role in OA development, as has been demonstrated both in vitro and in vivo. Stimulating autophagy with rapamycin (an inhibitor of mechanistic target of rapamycin kinase (mTOR) stimulating autophagy) in normal human knee articular chondrocytes resulted in decreased IL1 $\beta$-induced expression of OA genes, such as MMP13 and ADAMTS5, whereas inhibition of autophagy by siRNA targeting ATG5, an essential protein in the autophagy process, increased levels of these ECM-degrading enzymes [162]. In vivo, intra-articular injection of rapamycin in the DMM OA mouse model revealed decreased cartilage degeneration [163], whereas inhibition of autophagy with 3-methyladenine, a type III phosphatidylinositol 3-kinase (PI3K) inhibitor, in a collagenase rabbit OA model resulted in significantly aggravated cartilage degeneration [164].

Autophagy is coordinated by a large set of genes, called the ATG genes, which encode proteins that are essential in the consecutive steps of the autophagy process, such as proteins for the recruitment of cargo, formation of autophagosomes, and fusion with the lysosome. Examples of such ATG genes are Beclin-1, light chain 3 (LC3), and unc-51-like autophagy activating kinase 1 and 2 (ULK1/2) [165]. During the initial phase of OA, ATG gene expression is enhanced; for example, mRNA levels of Beclin-1 and $L C 3$ are increased in human articular knee OA chondrocytes compared to normal chondrocytes, whereas ATG gene expression decreases in late-stage OA [162]. This difference in kinetics is supported by an in-vivo observation: in a rabbit collagenase-induced OA model, authors demonstrated that the expression levels of autophagy markers Beclin-1 and Lc3 were increased at 2, 4, and 6 weeks after induction of the model, whereas levels were again decreased after 8 weeks [164].

The induction of ATG genes is, in general (thus probably also in OA), accompanied by epigenetic changes. Bromodomain-containing protein 4 (BRD4) is an epigenetic reader that recognizes acetylated histones, which acts as a repressor for ATG genes by recruiting the histone lysine methyltransferase G9a to the promoters of these genes (Figure 5) [166]. G9a hypermethylates the ATG gene promoters and thereby shuts off transcription. Importantly, BRD4 is active when there are sufficient nutrients present; however, under nutrient starvation, the AMP-activated protein kinase (AMPK), together with the deacetylase SIRT1, cause the dissociation of BRD4 from histone tails, leading to loss of its suppressor 
function and eventually resulting in the activation of ATG gene expression [166]. Whether BRD4 also plays a role in regulating ATG gene expression via these mechanisms in OA is not known but is likely because, in human OA knee cartilage, both mRNA and protein BRD4 levels were upregulated compared to normal cartilage, and BRD4 levels correlated positively with the severity of OA, indicating that BRD4 might also repress autophagy in OA chondrocytes [167]. Moreover, in a similar cell type as chondrocytes (nucleus pulposus cells), it was shown that inhibition of BRD4 by the protein inhibitor JQ1 resulted in enhanced autophagy [168]. Besides BRD4, SIRT1 is an important epigenetic remodeler that induces autophagy [169]. In SW1353 cells, knockdown of SIRT1 via siRNA resulted in decreased autophagy marker expression [170]. SIRT1 exerts its function through the deacetylation of ATG proteins; however, it also promotes autophagy by activating TFs of the FOXO family [171]. As previously mentioned, SIRT1 levels are elevated in early OA chondrocytes; however, SIRT1 levels decrease with OA severity $[83,85]$, which might partly explain the observation that autophagy is increased in early OA chondrocytes. As the process of autophagy encompasses many different genes, many different TFs are also involved in the transcriptional regulation of those genes. There are two TFs that are considered MRs of autophagy, namely, transcription factor EB (TFEB) and zinc-finger protein with KRAB and SCAN domains 3 (ZKSCAN3) [172,173]. TFEB and ZKSCAN3 have opposite functions in regulating autophagy. Overexpression of TFEB in HeLa cells induces autophagy [172], whereas silencing of ZKSCAN3 also induces autophagy [173]. Both in an OA mouse model (DMM) and human knee OA cartilage, a decline in TFEB expression was observed compared to normal cartilage [174]. Furthermore, overexpression of Tfeb in mouse chondrocytes resulted in upregulated expression of different autophagy genes, such as $L C 3$. In addition, knockdown of Tfeb by siRNA resulted in a decrease of autophagic flux, which is the dynamic process of forming autophagosomes and, eventually, autolysosomes, measured by LC3-II levels. TFEB is retained in the cytoplasm through phosphorylation by mTOR, leading to binding of TFEB to 14-3-3 phospho-binding proteins, which mask the nuclear localization signal, resulting in the retention of TFEB in the cytoplasm [175]. mTOR is shown to be upregulated in different animal models of OA and also in human OA cartilage $[176,177]$. Thus, besides the downregulated expression of TFEB in OA, its activity is also blocked by mTOR. In contrast to TFEB, ZKSCAN3 is a potent inhibitor of autophagy by repressing transcription of ATG genes such as ULK1 and LC3 [173]. However, the role of ZKSCAN3 in chondrocytes is not yet studied. Besides the two MRs of autophagy, other TFs also play a role in regulating the expression of ATG genes, such as different members of the FOXO TF family. FOXO TF family members, FOXO1 and FOXO3, are considered to be inducers of autophagy [156]. FOXO1 or FOXO1/FOXO3 knockdown via siRNA in human chondrocytes resulted in decreased expression of ATG genes in response to tert-butyl-hydroperoxide (tBHP)-induced oxidative stress [178]. Control transfected tBHP-stimulated chondrocytes upregulated expression of ATG genes such as LC3 and Beclin-1, while this expression was significantly reduced in FOXO1 and FOXO1/FOXO3 knockdown chondrocytes. Overexpression of constitutively active forms of FOXO (by mutating three phosphorylation sites) resulted in higher expression of $L C 3$ and Beclin-1 upon $\mathrm{tBHP}$ stimulation in OA chondrocytes. [178]. In addition, overexpression of this mutant FOXO1 form in healthy human chondrocytes increased the expression of $L C 3$ and Beclin-1 [179]. RNA sequencing revealed that levels of FOXO TFs were downregulated in OA cartilage compared to normal cartilage [42]. Furthermore, in both aging human cartilage and OA knee cartilage, FOXO1 and FOXO3 protein levels are reduced, together with increased phosphorylation of both FOXO TFs, resulting in cytoplasmic retention of the FOXO proteins [143]. The serine/threonine kinase AKT is one of the main kinases that phosphorylate the FOXO TFs, and the levels of activated AKT are higher in OA articular cartilage compared to normal articular cartilage [180]. Furthermore, in the DMM OA mouse model, the induction of activated AKT was observed with the progression of OA. In addition to FOXO TFs, numerous other TFs are also involved in regulating autophagy, such as p53, STAT3, NFKB, and C/EBP $\beta$ (reviewed in [156]). However, there is very little known about the role of these TFs in regulating autophagy in chondrocytes and OA. 


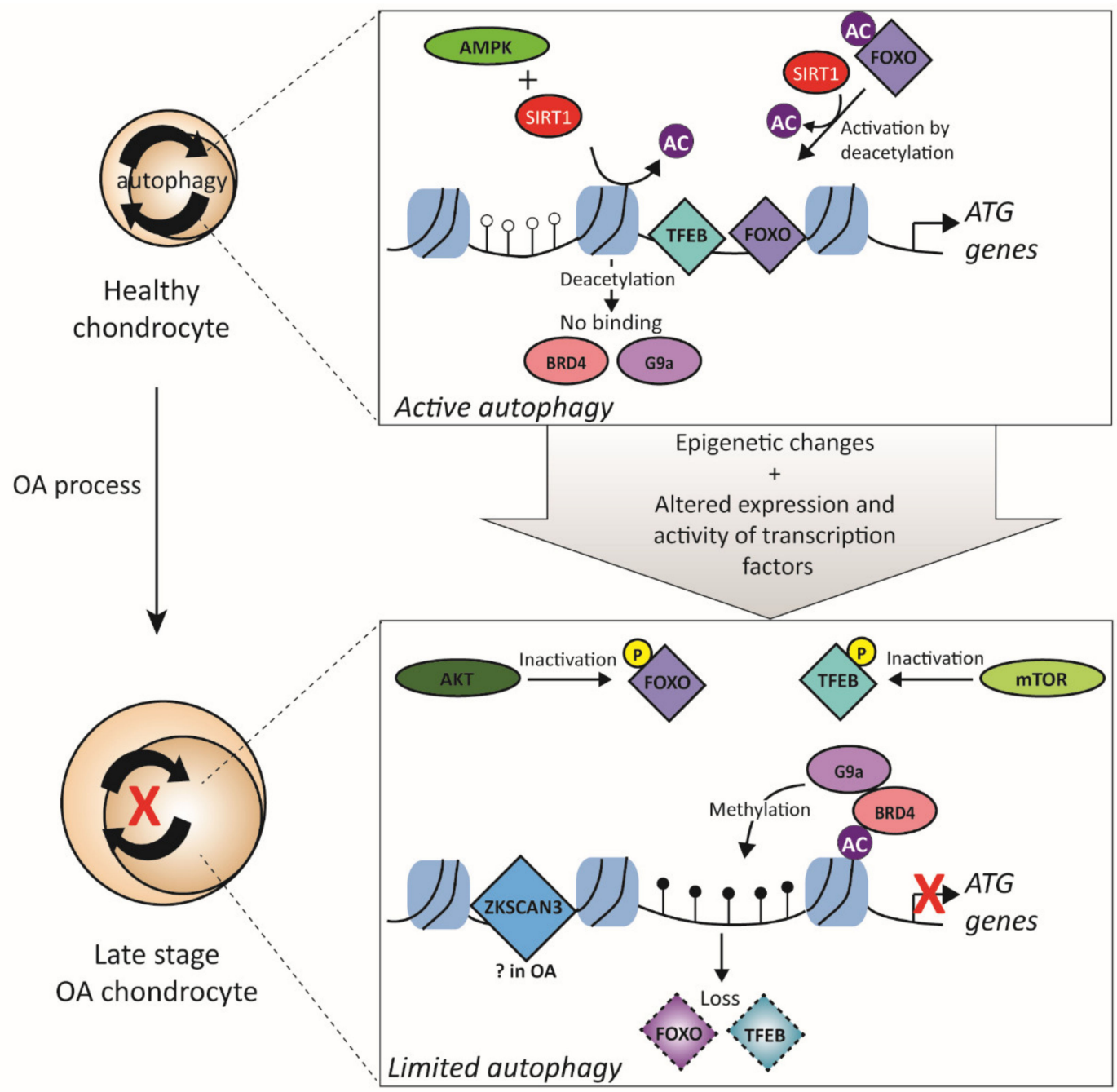

Figure 5. Transcription factors involved in autophagy. In a healthy chondrocyte, there is basal autophagy activity. AMPK and SIRT1 cause the release of BRD4 and the histone methyltransferase G9a via deacetylation of the histones. Furthermore, activating TFs such as TFEB can bind to the promoters of ATG genes and activate transcription. Another TF, FOXO, gets activated by deacetylation by SIRT1 and can, therefore, also activate transcription together with TFEB. In late-stage OA chondrocytes, autophagy is inhibited due to epigenetic changes and altered expression and activity of transcription factors. SIRT1 expression is downregulated in OA and, therefore, histone acetylation is not removed anymore. BRD4 binds to acetylated histone tails and recruits G9a, which hypermethylates the promoters of ATGs. Furthermore, expression of activating TFs such as TFEB and FOXO is downregulated, and their activity is also blocked by phosphorylation by AKT or mTOR. In addition, (probably), inhibitory TFs such as ZKSCAN3 are also recruited to the promoter regions. Together, this results in repression of ATGs transcription and declined autophagy in OA chondrocytes. AMPK = AMP-activated protein kinase; SIRT1 = sirtuin 1; BRD4 = bromodomain-containing protein 4; TFEB = transcription factor EB; ATG = autophagy-related; FOXO = forkhead box transcription factor class O; mTOR = mechanistic target of rapamycin kinase; ZKSCAN3 = zinc-finger protein with KRAB and SCAN domains 3.

\section{Transcription Factors as Therapeutic Targets}

There has been extensive research on the etiology of OA, and many attempts have been made to develop drugs to treat OA; however, none have been really successful. In the last decade, research has shifted from broad pathway analysis to more downstream signaling molecules, such asTFs, as druggable targets. A recent gain in knowledge of TF structure, function, expression patterns, and their interaction 
with other cofactors and the dynamics of DNA binding has helped to realize TFs as druggable targets (Figure 6). Different signaling molecules can activate different pathways that result in the use of the same TF for regulating their targeted gene expression, a phenomenon called redundancy. Therefore, targeting one signaling molecule will not necessarily diminish detrimental gene expression in a multifactorial environment such as OA. One example is that the two main ECM-degrading families, the MMPs and ADAMTSs, have some factors in their transcriptional machinery in common, such as $\mathrm{C} / \mathrm{EBP} \beta, \mathrm{HIF} 2 \alpha$, and RUNX2. Targeting these transcription factors might lead to better results asmultiple ECM-degrading enzymes are then targeted instead of only inhibiting one of the members.

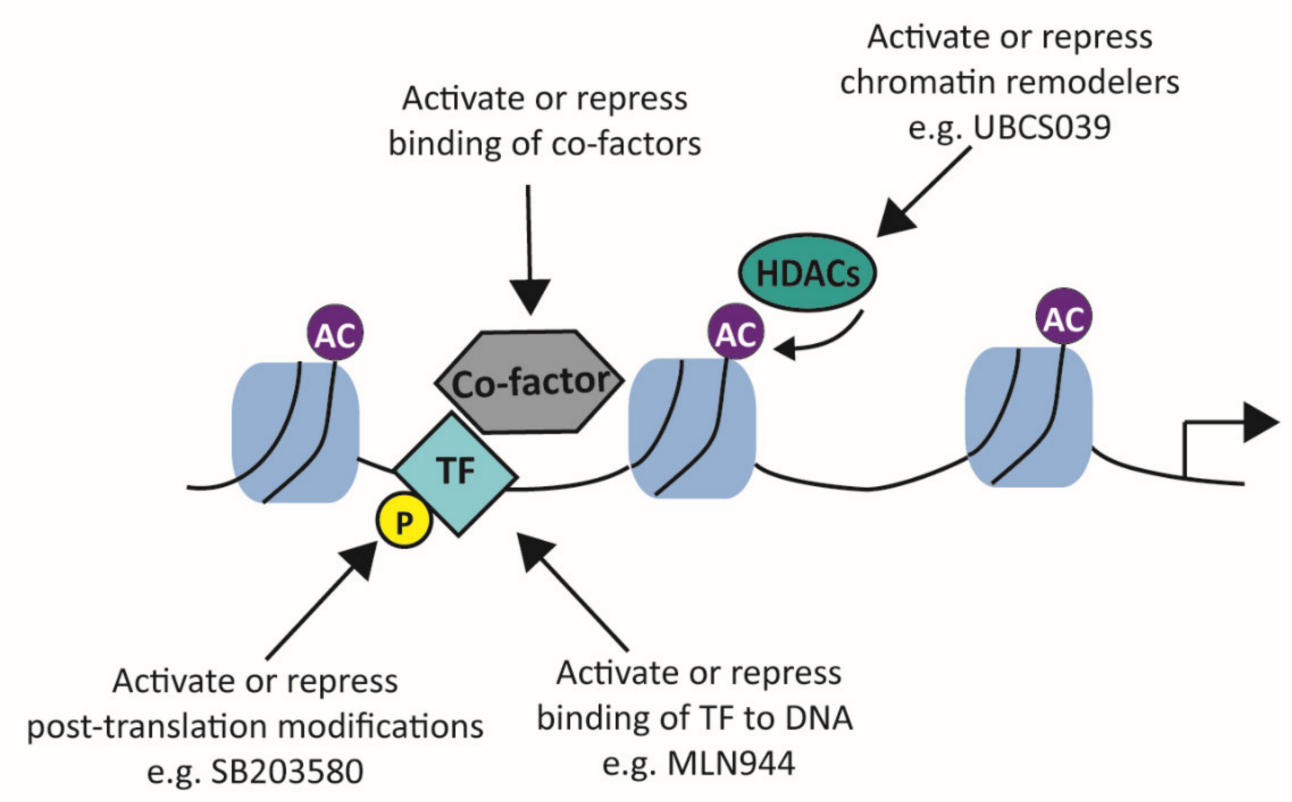

Figure 6. Possible therapeutic targets to regulate transcription factor function. There are different mechanisms that lead to transcription factor activation (or repression). Regulating these mechanisms can provide possible therapeutic targets. Activating or repressing the binding of cofactors, chromatin remodelers (e.g., UBCS039), and post-translational modifications (e.g., SB303580) or directly influencing the binding of transcription factors to DNA (e.g., MLN944) can be explored as therapeutic options. $\mathrm{TF}=$ transcription factors; HDAC $=$ histone deacetylase.

Furthermore, therapeutic options such as joint distraction, autologous stem cell transplantation, and even joint replacement demonstrate various degrees of clinical efficacy. One of the reasons why there is a huge variation among the efficacy of drugs or the above mentioned therapeutic options for OA is that $\mathrm{OA}$ is a heterogeneous disease, and, recently, it is thought that OA can be divided into different subtypes based on pathogenetic mechanisms and structural manifestations [181]. Subtyping based on the TF profile of a patient, i.e., which TFs are altered (e.g., activated or repressed), could be a valuable new way to approach treatment that has not been tried before, to our knowledge. The TF profile would give information about which key signaling pathways are activated and which process is the leading cause of OA. For example, the combination of high levels of the TFs AP-1 and RUNX2 might indicate that MMPs are the main drivers of OA, while high levels of the SOX proteins SOX4 and SOX11 might indicate more ADAMTS involvement. Subtyping based on TF profiles will help us understand the etiology of OA better and, together, will result in a more personalized medical treatment approach.

No drugs targeting transcription factors in OA are now on the market; however, transcription factors are also at the base of various other diseases such as cancer and multiple developmental disorders. A study into the role of transcription factors in human diseases implicated 164 TFs as directly linked to a human disease [182]. In the cancer field, 294 transcription factors have been found to be implicated in the disease [183], and some of these are also involved in regulating gene expression in the different processes 
of OA, such as JUN, SOX5, SOX9, ETS, and NFKB. MMP13, an important gene in OA development, is also implicated to play a role in the metastasis of cancer, and, here, the family of ETS transcription factors is also involved in regulation of $M M P 13$ expression [184]. The development of a small molecule inhibitor targeting the ETS family of transcription factors (YK-4-279) demonstrated reduced expression of MMP13 in a prostate cell line [185]. Another anticancer drug (MLN944) prevents the binding of JUN to the AP-1 binding motif in DNA by binding to the sequence itself [186]. Furthermore, double-stranded transcription factor decoy oligodeoxynucleotides (TFD ODNs) are short pieces of double-stranded DNA that mimic the binding site of a TF and, therefore, can act as decoys for a TF [187]. In a mouse model of asthma, TFD ODNs against NFKB and STAT6 inhibited inflammation by suppressing the overexpression of proinflammatory cytokines [188]. As inflammation induced by NFKB is also involved in OA (development), this may be an interesting drug to examine in OA mouse models. In addition, NFkB plays a crucial role in SASP, and it was shown that metformin, a drug that reduces SASP and senescence, achieves this by inhibiting the TF NFKB [189]. Another option is targeting STAT3, a transcription factor downstream of IL-6 signaling, which activates the expression of different proinflammatory cytokines. Inhibition of STAT3 activity by an STA3-selective inhibitor (STA21) resulted in decreased release of proinflammatory cytokines by mesenchymal stem cells isolated from OA patients [190]. Furthermore, in the MIA rat model, STA21 caused attenuation of arthritis development by inhibiting inflammation and cartilage damage, indicating that targeting STAT3 in OA might be beneficial.

Instead of repressing a pathogenic $\mathrm{TF}$, another option is either overexpressing (by pharmacologically inhibiting its degradation) or activating a TF with a positive action. SOX9, as the MR of chondrogenesis, is one of the most crucial TFs for keeping cartilage healthy, and loss of SOX9 is involved in upregulated hypertrophic differentiation, cellular senescence, and decreased ECM production. In vitro, overexpression of SOX9 in CHON-001 chondrocytes resulted in the decreased production of the inflammatory marker TNF $\alpha$ and decreased protein degradation of COL2A1 and SMAD3 [191]. In vivo, overexpression of SOX9 in a surgically induced OA mice model resulted in decreased proteoglycan loss and cartilage destruction, indicating that overexpression of SOX9 might protect against OA. Injection of the another anabolic TF RUNX1 via nanomicelles in an OA mice model resulted in diminished OA development as a result of increased SOX9 and COL2A1 protein expression in the RUNX1-injected group [192], indicating that indirect activation of SOX9 might also be a therapeutic possibility.

A third option would be activating or repressing chromatin remodelers as changing chromatin accessibility is often the first step towards acquired gene expression. For example, SIRT6 was shown to be important for inhibiting cellular senescence, and expression of SIRT6 was downregulated in OA, suggesting that activating SIRT6 could suppress senescence and SASP [139]. SIRT6 activators have been developed, and UBCS039 (a specific SIRT6 activator) has shown promising results in a human cancer cell line where it triggered autophagy [193]. Additionally, in rat articular chondrocytes, it has been shown that treatment with hydroxytyrosol results in SIRT6-mediated autophagy and thereby reduces chondrocyte senescence and SASP [194], indicating that activating chromatin remodelers might be helpful in treating OA.

TFs are essential regulators of transcription in every cell type and tissue, Y [195]. However, not much is known about the adverse effects of TF drugs in the clinic, as this is a recent and new field. In the cancer field, there is a lot of focus on a newly developed STAT3 inhibitor named bruceanitol. In an in-vivo study, bruceanitol was tested in a cancer mouse model via intraperitoneal injection, and no gross toxicities were determined concerning body weight; in addition, normal mouse colon tissue did not show signs of toxicity [196]. Furthermore, another TF-targeting drug, tamoxifen, which is a selective estrogen receptor modulator (SERM) that blocks ligand binding and, therefore, the conformational change necessary for the recruitment of cofactors, has been shown to be quite tissue-specific, likely due to other cofactors that are present in other cell types [197]. The SERM tamoxifen is already used in the clinic to treat breast cancer [198]. These results are promising for the development of other TF drugs. In addition, other approaches to target TFs that limit the adverse effects have also emerged, such as local injection or the use of nanodrug delivery systems ([199,200]). In OA, specific joints are often involved, which makes it 
likely that local injection of TF drugs can be beneficial without many side effects. The large joints, such as the knee, are excellent options for local injections, and a lot of OA patients already receive local steroid injections against the pain [201]. Another recently developed method is nanodrug delivery systems that are used to deliver drugs to a specific targeted site in a controlled manner via submicron-sized particles [202]. These particles can be modified to increase tissue retention, decrease renal clearance, or target a specific tissue. Drug delivery into the cartilage is very ineffective, and, therefore, nanodrugs may offer a solution. In a recent study, the growth factor insulin-like growth factor 1 (IGF-1) was conjugated to a nanocarrier designed to better infiltrate cartilage, and treatment of a surgical OA rat model with this IGF-1 nanodrug resulted in significantly less cartilage degeneration compared to treatment with free IGF-1 [203]. Together, these recent developments in both TF-targeting drugs and better local delivery systems are promising for the development of disease-modifying drugs for OA.

\section{Conclusions and Future Perspectives}

The most direct and effective treatment strategy for OA would be to target the transcriptional regulation machinery of genes involved in OA. The transcription factor profile, which can be used as a read-out for which signaling pathways are active, can help us understand the complex etiology of OA. In the last decade, more knowledge has been gained about TFs and how the transcriptional machinery is set in place to regulate transcription. In addition, in other fields where no therapy success is made yet with conventional targets, drug discovery is shifting towards targeting TFs. Drugs targeting TFs can possibly induce severe side effects; however, there are newly developed methods that could be used to limit this, such as a nanodrug delivery system. Further research into the method of drug delivery is needed to discover the most reliable and safe method. OA is known to be very heterogeneous, and efforts are being made to define different subtypes of OA. This transcription factor profile will help us define specific subgroups of OA and will aid a personalized treatment strategy for every patient. Of special interest are TFs that are differentially expressed in OA, but cofactor interactions and post-translational modifications might also be changed in OA. Together, these changes might explain why certain genes are up- or downregulated during OA.

Author Contributions: M.N., A.P.M.v.C. and P.M.v.d.K. conceptualized the idea. M.N. drafted the manuscript and created the figures. A.P.M.v.C. and P.M.v.d.K. evaluated the manuscript and edited the content. All authors have read and agreed to the published version of the manuscript.

Funding: This research was funded by a TTW Perspective Grant: William Hunter Revisited from NOW, grant number \#P15-23 and the APC was funded by the same grant.

Conflicts of Interest: The authors declare no conflict of interest.

\section{Abbreviations}

$\begin{array}{ll}\text { ACAN } & \text { aggrecan } \\ \text { ADAMTS } & \text { a disintegrin and metalloproteinase with thrombospondin motif } \\ \text { ALPL } & \text { alkaline phosphatase } \\ \text { AP-1 } & \text { activator protein } 1 \\ \text { ATF2 } & \text { activating transcription factor } 2 \\ \text { ATG } & \text { autophagy-related } \\ \text { BAPX-1 } & \text { homeobox protein Nkx-3.2 } \\ \text { C/EBP } & \text { CCAAT-enhancer-binding protein } \\ \text { COL10A1 } & \text { collagen type } X \\ \text { COL2A1 } & \text { collagen type II } \\ \text { CREB } & \text { cAMP response element binding protein } \\ \text { DMM } & \text { destabilization of the medial meniscus } \\ \text { ECM } & \text { extracellular matrix } \\ \text { ENaC } & \text { epithelial sodium channel }\end{array}$


ETS erythroblast transformation specific

FOXA forkhead box transcription factor class A

FOXO forkhead box transcription factor class $\mathrm{O}$

GATA4 GATA-binding factor 4

GLI glioma-associated oncogene

HAT histone acetyltransferase

HDAC histone deacetylase

HIF hypoxia-inducible factor

$\mathrm{IHH} \quad$ Indian hedgehog

IKK IKB kinase

IL interleukin

$\mathrm{KCa} \quad \mathrm{Ca}^{2+}$ activated potassium channels

LC3 light chain 3

MAPK mitogen-activated protein kinase

MEF2C myocyte-specific enhancer factor 2C

MMP matrix matalloproteinase

MR master regulator

mTOR mechanistic target of rapamycin kinase

MYOD myoblast determination protein

NFAT nuclear factor of activated T-cell

NFkB nuclear factor kappa B

$\mathrm{OA}$

osteoarthritis

PAX paired box

PI3K phosphatidylinositol 3-kinase

PITX1 paired-like homeodomain 1

PKA cAMP-dependent protein kinase A

PTHrP parathyroid hormone-like protein

RUNX2 runt-related transcription factor 2

SASP Senescence-associated secretory phenotype

siRNA small interfering RNA

SIRT1 sirtuin 1

SMAD3 SMAD family member 3

SOX9 SRY-BOX transcription factor 9

SP1 specificity protein 1

STAT3 signal transducer and activator of transcription 3

T3 active thyroid hormone

TASK-2 Acid-sensing potassium channel

tBHP tert-butyl-hydroperoxide

TCF/LEF T-cell factor/lymphoid enhancer factor

TF transcription factor

TFD ODN transcription factor decoy oligodeoxynucleotides

TFEB transcription factor EB

TGF $\beta \quad$ transforming growth factor $\beta$

TMEM16 $\quad \mathrm{Ca}^{2+}$ activated chloride channel

TNF $\alpha \quad$ tumor necrosis factor alpha

TSS transcription start site

ULK1/2 unc-51-like autophagy activating kinase 1 and 2

ZKSCAN3 zinc-finger protein with KRAB and SCAN domain 3

\section{References}

1. Hunter, D.J.; Schofield, D.; Callander, E. The individual and socioeconomic impact of osteoarthritis. Nat. Rev. Rheumatol. 2014, 10, 437-441. [CrossRef] [PubMed]

2. Oo, W.M.; Yu, S.P.; Daniel, M.S.; Hunter, D.J. Disease-modifying drugs in osteoarthritis: Current understanding and future therapeutics. Expert Opin. Emerg. Drugs 2018, 23, 331-347. [CrossRef] [PubMed] 
3. Carballo, C.B.; Nakagawa, Y.; Sekiya, I.; Rodeo, S.A. Basic Science of Articular Cartilage. Clin. Sports Med. 2017, 36, 413-425. [CrossRef] [PubMed]

4. Simon, T.M.; Jackson, D.W. Articular Cartilage: Injury Pathways and Treatment Options. Sports Med. Arthrosc. Rev. 2018, 26, 31-39. [CrossRef] [PubMed]

5. Sophia Fox, A.J.; Bedi, A.; Rodeo, S.A. The basic science of articular cartilage: Structure, composition, and function. Sports Health 2009, 1, 461-468. [CrossRef] [PubMed]

6. Cucchiarini, M.; de Girolamo, L.; Filardo, G.; Oliveira, J.M.; Orth, P.; Pape, D.; Reboul, P. Basic science of osteoarthritis. J. Exp. Orthop. 2016, 3, 22. [CrossRef]

7. Loeser, R.F. Aging and osteoarthritis: The role of chondrocyte senescence and aging changes in the cartilage matrix. Osteoarthr. Cartil. 2009, 17, 971-979. [CrossRef]

8. van der Kraan, P.M.; van den Berg, W.B. Chondrocyte hypertrophy and osteoarthritis: Role in initiation and progression of cartilage degeneration? Osteoarthr. Cartil. 2012, 20, 223-232. [CrossRef]

9. Lin, C.Y.; Loven, J.; Rahl, P.B.; Paranal, R.M.; Burge, C.B.; Bradner, J.E.; Lee, T.I.; Young, R.A. Transcriptional amplification in tumor cells with elevated c-Myc. Cell 2012, 151, 56-67. [CrossRef]

10. Pattabiraman, D.R.; McGirr, C.; Shakhbazov, K.; Barbier, V.; Krishnan, K.; Mukhopadhyay, P.; Hawthorne, P.; Trezise, A.; Ding, J.; Grimmond, S.M.; et al. Interaction of c-Myb with p300 is required for the induction of acute myeloid leukemia (AML) by human AML oncogenes. Blood 2014, 123, 2682-2690. [CrossRef]

11. Boyadjiev, S.A.; Jabs, E.W. Online Mendelian Inheritance in Man (OMIM) as a knowledgebase for human developmental disorders. Clin. Genet. 2000, 57, 253-266. [CrossRef] [PubMed]

12. Wang, L.; Fan, C.; Topol, S.E.; Topol, E.J.; Wang, Q. Mutation of MEF2A in an inherited disorder with features of coronary artery disease. Science 2003, 302, 1578-1581. [CrossRef] [PubMed]

13. Akirav, E.M.; Ruddle, N.H.; Herold, K.C. The role of AIRE in human autoimmune disease. Nat. Rev. Endocrinol. 2011, 7, 25-33. [CrossRef]

14. Garrett-Sinha, L.A.; Kearly, A.; Satterthwaite, A.B. The Role of the Transcription Factor Ets1 in Lupus and Other Autoimmune Diseases. Crit. Rev. Immunol. 2016, 36, 485-510. [CrossRef]

15. Lambert, S.A.; Jolma, A.; Campitelli, L.F.; Das, P.K.; Yin, Y.; Albu, M.; Chen, X.; Taipale, J.; Hughes, T.R.; Weirauch, M.T. The Human Transcription Factors. Cell 2018, 175, 598-599. [CrossRef] [PubMed]

16. Latchman, D.S. Transcription factors: An overview. Int. J. Exp. Pathol. 1993, 74, 417-422. [CrossRef]

17. Dynlacht, B.D. Regulation of transcription by proteins that control the cell cycle. Nature 1997, 389, $149-152$. [CrossRef]

18. Accili, D.; Arden, K.C. FoxOs at the crossroads of cellular metabolism, differentiation, and transformation. Cell 2004, 117, 421-426. [CrossRef]

19. Fulton, D.L.; Sundararajan, S.; Badis, G.; Hughes, T.R.; Wasserman, W.W.; Roach, J.C.; Sladek, R. TFCat: The curated catalog of mouse and human transcription factors. Genome Biol. 2009, 10, R29. [CrossRef]

20. Babu, M.M.; Luscombe, N.M.; Aravind, L.; Gerstein, M.; Teichmann, S.A. Structure and evolution of transcriptional regulatory networks. Curr. Opin. Struct. Biol. 2004, 14, 283-291. [CrossRef]

21. Roeder, R.G. The role of general initiation factors in transcription by RNA polymerase II. Trends Biochem. Sci. 1996, 21, 327-335. [CrossRef]

22. Chan, S.S.; Kyba, M. What is a Master Regulator? J. Stem. Cell Res. Ther. 2013, 3. [CrossRef]

23. Iwafuchi-Doi, M.; Zaret, K.S. Cell fate control by pioneer transcription factors. Development 2016, 143, $1833-1837$. [CrossRef] [PubMed]

24. Lassar, A.B.; Paterson, B.M.; Weintraub, H. Transfection of a DNA locus that mediates the conversion of 10T1/2 fibroblasts to myoblasts. Cell 1986, 47, 649-656. [CrossRef]

25. Maston, G.A.; Evans, S.K.; Green, M.R. Transcriptional regulatory elements in the human genome. Annu. Rev. Genom. Hum. Genet. 2006, 7, 29-59. [CrossRef] [PubMed]

26. Spitz, F.; Furlong, E.E. Transcription factors: From enhancer binding to developmental control. Nat. Rev. Genet. 2012, 13, 613-626. [CrossRef] [PubMed]

27. Kim, S.; Shendure, J. Mechanisms of Interplay between Transcription Factors and the 3D Genome. Mol. Cell 2019, 76, 306-319. [CrossRef] [PubMed]

28. Inukai, S.; Kock, K.H.; Bulyk, M.L. Transcription factor-DNA binding: Beyond binding site motifs. Curr. Opin. Genet. Dev. 2017, 43, 110-119. [CrossRef] 
29. Mulero, M.C.; Shahabi, S.; Ko, M.S.; Schiffer, J.M.; Huang, D.B.; Wang, V.Y.; Amaro, R.E.; Huxford, T.; Ghosh, G. Protein Cofactors Are Essential for High-Affinity DNA Binding by the Nuclear Factor kappaB RelA Subunit. Biochemistry 2018, 57, 2943-2957. [CrossRef]

30. Fiering, S.; Northrop, J.P.; Nolan, G.P.; Mattila, P.S.; Crabtree, G.R.; Herzenberg, L.A. Single cell assay of a transcription factor reveals a threshold in transcription activated by signals emanating from the T-cell antigen receptor. Genes Dev. 1990, 4, 1823-1834. [CrossRef]

31. Giorgetti, L.; Siggers, T.; Tiana, G.; Caprara, G.; Notarbartolo, S.; Corona, T.; Pasparakis, M.; Milani, P.; Bulyk, M.L.; Natoli, G. Noncooperative interactions between transcription factors and clustered DNA binding sites enable graded transcriptional responses to environmental inputs. Mol. Cell 2010, 37, 418-428. [CrossRef] [PubMed]

32. Mullen, A.C.; Orlando, D.A.; Newman, J.J.; Loven, J.; Kumar, R.M.; Bilodeau, S.; Reddy, J.; Guenther, M.G.; DeKoter, R.P.; Young, R.A. Master transcription factors determine cell-type-specific responses to TGF-beta signaling. Cell 2011, 147, 565-576. [CrossRef] [PubMed]

33. Chen, L.F.; Williams, S.A.; Mu, Y.; Nakano, H.; Duerr, J.M.; Buckbinder, L.; Greene, W.C. NF-kappaB RelA phosphorylation regulates RelA acetylation. Mol. Cell. Biol. 2005, 25, 7966-7975. [CrossRef] [PubMed]

34. Bi, W.; Deng, J.M.; Zhang, Z.; Behringer, R.R.; de Crombrugghe, B. Sox9 is required for cartilage formation. Nat. Genet. 1999, 22, 85-89. [CrossRef] [PubMed]

35. Lefebvre, V.; Dvir-Ginzberg, M. SOX9 and the many facets of its regulation in the chondrocyte lineage. Connect. Tissue Res. 2017, 58, 2-14. [CrossRef]

36. Ashraf, S.; Cha, B.H.; Kim, J.S.; Ahn, J.; Han, I.; Park, H.; Lee, S.H. Regulation of senescence associated signaling mechanisms in chondrocytes for cartilage tissue regeneration. Osteoarthr. Cartil. 2016, 24, 196-205. [CrossRef]

37. Akiyama, H.; Chaboissier, M.C.; Martin, J.F.; Schedl, A.; de Crombrugghe, B. The transcription factor Sox 9 has essential roles in successive steps of the chondrocyte differentiation pathway and is required for expression of Sox5 and Sox6. Genes Dev. 2002, 16, 2813-2828. [CrossRef]

38. Csukasi, F.; Duran, I.; Zhang, W.; Martin, J.H.; Barad, M.; Bamshad, M.; Weis, M.A.; Eyre, D.; Krakow, D.; Cohn, D.H. Dominant-negative SOX9 mutations in campomelic dysplasia. Hum. Mutat. 2019, 40, $2344-2352$. [CrossRef]

39. Tew, S.R.; Clegg, P.D.; Brew, C.J.; Redmond, C.M.; Hardingham, T.E. SOX9 transduction of a human chondrocytic cell line identifies novel genes regulated in primary human chondrocytes and in osteoarthritis. Arthritis Res. Ther. 2007, 9, R107. [CrossRef]

40. Zhong, L.; Huang, X.; Karperien, M.; Post, J.N. Correlation between Gene Expression and Osteoarthritis Progression in Human. Int. J. Mol. Sci. 2016, 17, 1126. [CrossRef]

41. Liu, Y.; Chang, J.C.; Hon, C.C.; Fukui, N.; Tanaka, N.; Zhang, Z.; Lee, M.T.M.; Minoda, A. Chromatin accessibility landscape of articular knee cartilage reveals aberrant enhancer regulation in osteoarthritis. Sci. Rep. 2018, 8, 15499. [CrossRef] [PubMed]

42. Fisch, K.M.; Gamini, R.; Alvarez-Garcia, O.; Akagi, R.; Saito, M.; Muramatsu, Y.; Sasho, T.; Koziol, J.A.; $\mathrm{Su}$, A.I.; Lotz, M.K. Identification of transcription factors responsible for dysregulated networks in human osteoarthritis cartilage by global gene expression analysis. Osteoarthr. Cartil. 2018, 26, 1531-1538. [CrossRef] [PubMed]

43. Gao, X.; Sun, Y.; Li, X. Identification of key gene modules and transcription factors for human osteoarthritis by weighted gene co-expression network analysis. Exp. Ther. Med. 2019, 18, 2479-2490. [CrossRef] [PubMed]

44. Thielen, N.G.M.; van der Kraan, P.M.; van Caam, A.P.M. TGFbeta/BMP Signaling Pathway in Cartilage Homeostasis. Cells 2019, 8, 969. [CrossRef]

45. Yan, D.; Davis, F.J.; Sharrocks, A.D.; Im, H.J. Emerging roles of SUMO modification in arthritis. Gene 2010, 466, 1-15. [CrossRef] [PubMed]

46. Prasadam, I.; Mao, X.; Wang, Y.; Shi, W.; Crawford, R.; Xiao, Y. Inhibition of p38 pathway leads to OA-like changes in a rat animal model. Rheumatology (Oxford) 2012, 51, 813-823. [CrossRef]

47. Sun, H.Y.; Hu, K.Z.; Yin, Z.S. Inhibition of the p38-MAPK signaling pathway suppresses the apoptosis and expression of proinflammatory cytokines in human osteoarthritis chondrocytes. Cytokine 2017, 90, 135-143. [CrossRef] [PubMed]

48. Fan, Z.; Soder, S.; Oehler, S.; Fundel, K.; Aigner, T. Activation of interleukin-1 signaling cascades in normal and osteoarthritic articular cartilage. Am. J. Pathol. 2007, 171, 938-946. [CrossRef] 
49. Martel-Pelletier, J.; Mineau, F.; Jovanovic, D.; Di Battista, J.A.; Pelletier, J.P. Mitogen-activated protein kinase and nuclear factor kappaB together regulate interleukin-17-induced nitric oxide production in human osteoarthritic chondrocytes: Possible role of transactivating factor mitogen-activated protein kinase-activated proten kinase (MAPKAPK). Arthritis Rheum. 1999, 42, 2399-2409. [CrossRef]

50. Kelwick, R.; Desanlis, I.; Wheeler, G.N.; Edwards, D.R. The ADAMTS (A Disintegrin and Metalloproteinase with Thrombospondin motifs) family. Genome Biol. 2015, 16, 113. [CrossRef]

51. Jablonska-Trypuc, A.; Matejczyk, M.; Rosochacki, S. Matrix metalloproteinases (MMPs), the main extracellular matrix (ECM) enzymes in collagen degradation, as a target for anticancer drugs. J. Enzyme Inhib. Med. Chem. 2016, 31, 177-183. [CrossRef] [PubMed]

52. Troeberg, L.; Nagase, H. Proteases involved in cartilage matrix degradation in osteoarthritis. Biochim. Biophys. Acta 2012, 1824, 133-145. [CrossRef] [PubMed]

53. Matyas, J.R.; Adams, M.E.; Huang, D.; Sandell, L.J. Discoordinate gene expression of aggrecan and type II collagen in experimental osteoarthritis. Arthritis Rheum. 1995, 38, 420-425. [CrossRef]

54. Sandy, J.D.; Adams, M.E.; Billingham, M.E.; Plaas, A.; Muir, H. In vivo and in vitro stimulation of chondrocyte biosynthetic activity in early experimental osteoarthritis. Arthritis Rheum. 1984, 27, 388-397. [CrossRef] [PubMed]

55. Roach, H.I.; Yamada, N.; Cheung, K.S.; Tilley, S.; Clarke, N.M.; Oreffo, R.O.; Kokubun, S.; Bronner, F. Association between the abnormal expression of matrix-degrading enzymes by human osteoarthritic chondrocytes and demethylation of specific CpG sites in the promoter regions. Arthritis Rheum. 2005, 52, 3110-3124. [CrossRef] [PubMed]

56. Bird, A.P.; Wolffe, A.P. Methylation-induced repression-belts, braces, and chromatin. Cell 1999, 99, $451-454$. [CrossRef]

57. Bui, C.; Barter, M.J.; Scott, J.L.; Xu, Y.; Galler, M.; Reynard, L.N.; Rowan, A.D.; Young, D.A. cAMP response element-binding (CREB) recruitment following a specific CpG demethylation leads to the elevated expression of the matrix metalloproteinase 13 in human articular chondrocytes and osteoarthritis. FASEB J. 2012, 26, 3000-3011. [CrossRef]

58. Cheung, K.S.; Hashimoto, K.; Yamada, N.; Roach, H.I. Expression of ADAMTS-4 by chondrocytes in the surface zone of human osteoarthritic cartilage is regulated by epigenetic DNA de-methylation. Rheumatol. Int. 2009, 29, 525-534. [CrossRef]

59. Richardson, B. Impact of aging on DNA methylation. Ageing Res. Rev. 2003, 2, 245-261. [CrossRef]

60. Hashimoto, K.; Oreffo, R.O.; Gibson, M.B.; Goldring, M.B.; Roach, H.I. DNA demethylation at specific CpG sites in the IL1B promoter in response to inflammatory cytokines in human articular chondrocytes. Arthritis Rheum. 2009, 60, 3303-3313. [CrossRef]

61. Roach, H.I.; Aigner, T. DNA methylation in osteoarthritic chondrocytes: A new molecular target. Osteoarthr. Cartil. 2007, 15, 128-137. [CrossRef] [PubMed]

62. Huang, C.Y.; Lin, H.J.; Chen, H.S.; Cheng, S.Y.; Hsu, H.C.; Tang, C.H. Thrombin promotes matrix metalloproteinase-13 expression through the PKCdelta c-Src/EGFR/PI3K/Akt/AP-1 signaling pathway in human chondrocytes. Mediat. Inflamm. 2013, 2013, 326041. [CrossRef] [PubMed]

63. Yan, C.; Boyd, D.D. Regulation of matrix metalloproteinase gene expression. J. Cell. Physiol. 2007, 211, 19-26. [CrossRef] [PubMed]

64. Yun, K.; Im, S.H. Transcriptional regulation of MMP13 by Lef1 in chondrocytes. Biochem. Biophys. Res. Commun. 2007, 364, 1009-1014. [CrossRef] [PubMed]

65. Kobayashi, H.; Hirata, M.; Saito, T.; Itoh, S.; Chung, U.I.; Kawaguchi, H. Transcriptional induction of ADAMTS5 protein by nuclear factor-kappaB (NF-kappaB) family member RelA/p65 in chondrocytes during osteoarthritis development. J. Biol. Chem. 2013, 288, 28620-28629. [CrossRef]

66. Takahata, Y.; Nakamura, E.; Hata, K.; Wakabayashi, M.; Murakami, T.; Wakamori, K.; Yoshikawa, H.; Matsuda, A.; Fukui, N.; Nishimura, R. Sox4 is involved in osteoarthritic cartilage deterioration through induction of ADAMTS4 and ADAMTS5. FASEB J. 2019, 33, 619-630. [CrossRef]

67. Aikawa, Y.; Morimoto, K.; Yamamoto, T.; Chaki, H.; Hashiramoto, A.; Narita, H.; Hirono, S.; Shiozawa, S. Treatment of arthritis with a selective inhibitor of c-Fos/activator protein-1. Nat. Biotechnol. 2008, 26, 817-823. [CrossRef] 
68. Motomura, H.; Seki, S.; Shiozawa, S.; Aikawa, Y.; Nogami, M.; Kimura, T. A selective c-Fos/AP-1 inhibitor prevents cartilage destruction and subsequent osteophyte formation. Biochem. Biophys. Res. Commun. 2018, 497, 756-761. [CrossRef]

69. Haag, J.; Gebhard, P.M.; Aigner, T. SOX gene expression in human osteoarthritic cartilage. Pathobiology 2008, 75, 195-199. [CrossRef]

70. Choi, M.C.; Jo, J.; Park, J.; Kang, H.K.; Park, Y. NF-kappaB Signaling Pathways in Osteoarthritic Cartilage Destruction. Cells 2019, 8, 734. [CrossRef]

71. Chen, L.X.; Lin, L.; Wang, H.J.; Wei, X.L.; Fu, X.; Zhang, J.Y.; Yu, C.L. Suppression of early experimental osteoarthritis by in vivo delivery of the adenoviral vector-mediated NF-kappaBp65-specific siRNA. Osteoarthr. Cartil. 2008, 16, 174-184. [CrossRef]

72. Murahashi, Y.; Yano, F.; Kobayashi, H.; Makii, Y.; Iba, K.; Yamashita, T.; Tanaka, S.; Saito, T. Intra-articular administration of IkappaBalpha kinase inhibitor suppresses mouse knee osteoarthritis via downregulation of the NF-kappaB/HIF-2alpha axis. Sci. Rep. 2018, 8, 16475. [CrossRef] [PubMed]

73. Ma, B.; Zhong, L.; van Blitterswijk, C.A.; Post, J.N.; Karperien, M. T cell factor 4 is a pro-catabolic and apoptotic factor in human articular chondrocytes by potentiating nuclear factor kappaB signaling. J. Biol. Chem. 2013, 288, 17552-17558. [CrossRef]

74. Deshmukh, V.; Hu, H.; Barroga, C.; Bossard, C.; Kc, S.; Dellamary, L.; Stewart, J.; Chiu, K.; Ibanez, M.; Pedraza, M.; et al. A small-molecule inhibitor of the Wnt pathway (SM04690) as a potential disease modifying agent for the treatment of osteoarthritis of the knee. Osteoarthr. Cartil. 2018, 26, 18-27. [CrossRef] [PubMed]

75. Yazici, Y.; McAlindon, T.E.; Fleischmann, R.; Gibofsky, A.; Lane, N.E.; Kivitz, A.J.; Skrepnik, N.; Armas, E.; Swearingen, C.J.; DiFrancesco, A.; et al. A novel Wnt pathway inhibitor, SM04690, for the treatment of moderate to severe osteoarthritis of the knee: Results of a 24-week, randomized, controlled, phase 1 study. Osteoarthr. Cartil. 2017, 25, 1598-1606. [CrossRef] [PubMed]

76. Martel-Pelletier, J.; Boileau, C.; Pelletier, J.P.; Roughley, P.J. Cartilage in normal and osteoarthritis conditions. Best Pract. Res. Clin. Rheumatol. 2008, 22, 351-384. [CrossRef] [PubMed]

77. Hu, G.; Codina, M.; Fisher, S. Multiple enhancers associated with ACAN suggest highly redundant transcriptional regulation in cartilage. Matrix Biol. 2012, 31, 328-337. [CrossRef]

78. Zhang, Q.; Ji, Q.; Wang, X.; Kang, L.; Fu, Y.; Yin, Y.; Li, Z.; Liu, Y.; Xu, X.; Wang, Y. SOX9 is a regulator of ADAMTSs-induced cartilage degeneration at the early stage of human osteoarthritis. Osteoarthr. Cartil. 2015, 23, 2259-2268. [CrossRef]

79. Dunn, S.L.; Soul, J.; Anand, S.; Schwartz, J.M.; Boot-Handford, R.P.; Hardingham, T.E. Gene expression changes in damaged osteoarthritic cartilage identify a signature of non-chondrogenic and mechanical responses. Osteoarthr. Cartil. 2016, 24, 1431-1440. [CrossRef]

80. Zwickl, H.; Niculescu-Morzsa, E.; Halbwirth, F.; Bauer, C.; Jeyakumar, V.; Reutterer, A.; Berger, M.; Nehrer, S. Correlation Analysis of SOX9, -5 , and -6 as well as COL2A1 and Aggrecan Gene Expression of Collagen I Implant-Derived and Osteoarthritic Chondrocytes. Cartilage 2016, 7, 185-192. [CrossRef]

81. Huang, W.; Zhou, X.; Lefebvre, V.; de Crombrugghe, B. Phosphorylation of SOX9 by cyclic AMP-dependent protein kinase A enhances SOX9's ability to transactivate a Col2a1 chondrocyte-specific enhancer. Mol. Cell. Biol. 2000, 20, 4149-4158. [CrossRef] [PubMed]

82. Dvir-Ginzberg, M.; Gagarina, V.; Lee, E.J.; Hall, D.J. Regulation of cartilage-specific gene expression in human chondrocytes by SirT1 and nicotinamide phosphoribosyltransferase. J. Biol. Chem. 2008, 283, 36300-36310. [CrossRef] [PubMed]

83. Liu, S.; Yang, H.; Hu, B.; Zhang, M. Sirt1 regulates apoptosis and extracellular matrix degradation in resveratrol-treated osteoarthritis chondrocytes via the Wnt/beta-catenin signaling pathways. Exp. Ther. Med. 2017, 14, 5057-5062. [CrossRef] [PubMed]

84. Matsushita, T.; Sasaki, H.; Takayama, K.; Ishida, K.; Matsumoto, T.; Kubo, S.; Matsuzaki, T.; Nishida, K.; Kurosaka, M.; Kuroda, R. The overexpression of SIRT1 inhibited osteoarthritic gene expression changes induced by interleukin-1beta in human chondrocytes. J. Orthop. Res. 2013, 31, 531-537. [CrossRef] [PubMed]

85. Fujita, N.; Matsushita, T.; Ishida, K.; Kubo, S.; Matsumoto, T.; Takayama, K.; Kurosaka, M.; Kuroda, R. Potential involvement of SIRT1 in the pathogenesis of osteoarthritis through the modulation of chondrocyte gene expressions. J. Orthop. Res. 2011, 29, 511-515. [CrossRef] 
86. Hattori, T.; Kishino, T.; Stephen, S.; Eberspaecher, H.; Maki, S.; Takigawa, M.; de Crombrugghe, B.; Yasuda, H. E6-AP/UBE3A protein acts as a ubiquitin ligase toward SOX9 protein. J. Biol. Chem. 2013, 288, 35138-35148. [CrossRef]

87. Furumatsu, T.; Tsuda, M.; Taniguchi, N.; Tajima, Y.; Asahara, H. Smad3 induces chondrogenesis through the activation of SOX9 via CREB-binding protein/p300 recruitment. J. Biol. Chem. 2005, 280, 8343-8350. [CrossRef]

88. Zhang, M.; Lu, Q.; Budden, T.; Wang, J. NFAT1 protects articular cartilage against osteoarthritic degradation by directly regulating transcription of specific anabolic and catabolic genes. Bone Joint Res. 2019, 8, 90-100. [CrossRef]

89. Ghayor, C.; Chadjichristos, C.; Herrouin, J.F.; Ala-Kokko, L.; Suske, G.; Pujol, J.P.; Galera, P. Sp3 represses the Sp1-mediated transactivation of the human COL2A1 gene in primary and de-differentiated chondrocytes. J. Biol. Chem. 2001, 276, 36881-36895. [CrossRef]

90. Wang, J.; Gardner, B.M.; Lu, Q.; Rodova, M.; Woodbury, B.G.; Yost, J.G.; Roby, K.F.; Pinson, D.M.; Tawfik, O.; Anderson, H.C. Transcription factor Nfat1 deficiency causes osteoarthritis through dysfunction of adult articular chondrocytes. J. Pathol. 2009, 219, 163-172. [CrossRef]

91. Ghayor, C.; Herrouin, J.F.; Chadjichristos, C.; Ala-Kokko, L.; Takigawa, M.; Pujol, J.P.; Galera, P. Regulation of human COL2A1 gene expression in chondrocytes. Identification of C-Krox-responsive elements and modulation by phenotype alteration. J. Biol. Chem. 2000, 275, 27421-27438. [CrossRef] [PubMed]

92. Chadjichristos, C.; Ghayor, C.; Kypriotou, M.; Martin, G.; Renard, E.; Ala-Kokko, L.; Suske, G.; de Crombrugghe, B.; Pujol, J.P.; Galera, P. Sp1 and Sp3 transcription factors mediate interleukin-1 beta down-regulation of human type II collagen gene expression in articular chondrocytes. J. Biol. Chem. 2003, 278, 39762-39772. [CrossRef] [PubMed]

93. Finnson, K.W.; Parker, W.L.; ten Dijke, P.; Thorikay, M.; Philip, A. ALK1 opposes ALK5/Smad3 signaling and expression of extracellular matrix components in human chondrocytes. J. Bone Miner. Res. 2008, 23, 896-906. [CrossRef] [PubMed]

94. de Kroon, L.M.; Narcisi, R.; van den Akker, G.G.; Vitters, E.L.; Blaney Davidson, E.N.; van Osch, G.J.; van der Kraan, P.M. SMAD3 and SMAD4 have a more dominant role than SMAD2 in TGFbeta-induced chondrogenic differentiation of bone marrow-derived mesenchymal stem cells. Sci. Rep. 2017, 7, 43164. [CrossRef]

95. Blaney Davidson, E.N.; Remst, D.F.; Vitters, E.L.; van Beuningen, H.M.; Blom, A.B.; Goumans, M.J.; van den Berg, W.B.; van der Kraan, P.M. Increase in ALK1/ALK5 ratio as a cause for elevated MMP-13 expression in osteoarthritis in humans and mice. J. Immunol. 2009, 182, 7937-7945. [CrossRef] [PubMed]

96. Retting, K.N.; Song, B.; Yoon, B.S.; Lyons, K.M. BMP canonical Smad signaling through Smad1 and Smad5 is required for endochondral bone formation. Development 2009, 136, 1093-1104. [CrossRef]

97. Sun, M.M.; Beier, F. Chondrocyte hypertrophy in skeletal development, growth, and disease. Birth Defects Res. C Embryo Today 2014, 102, 74-82. [CrossRef] [PubMed]

98. Ripmeester, E.G.J.; Timur, U.T.; Caron, M.M.J.; Welting, T.J.M. Recent Insights into the Contribution of the Changing Hypertrophic Chondrocyte Phenotype in the Development and Progression of Osteoarthritis. Front. Bioeng. Biotechnol. 2018, 6, 18. [CrossRef]

99. Hall, A.C. The Role of Chondrocyte Morphology and Volume in Controlling Phenotype-Implications for Osteoarthritis, Cartilage Repair, and Cartilage Engineering. Curr. Rheumatol. Rep. 2019, 21, 38. [CrossRef]

100. Lewis, R.; Feetham, C.H.; Barrett-Jolley, R. Cell volume regulation in chondrocytes. Cell. Physiol. Biochem. 2011, 28, 1111-1122. [CrossRef]

101. Mobasheri, A.; Lewis, R.; Ferreira-Mendes, A.; Rufino, A.; Dart, C.; Barrett-Jolley, R. Potassium channels in articular chondrocytes. Channels (Austin) 2012, 6, 416-425. [CrossRef] [PubMed]

102. Soul, J.; Dunn, S.L.; Anand, S.; Serracino-Inglott, F.; Schwartz, J.M.; Boot-Handford, R.P.; Hardingham, T.E. Stratification of knee osteoarthritis: Two major patient subgroups identified by genome-wide expression analysis of articular cartilage. Ann. Rheum. Dis. 2018, 77, 423. [CrossRef] [PubMed]

103. Karlsson, C.; Dehne, T.; Lindahl, A.; Brittberg, M.; Pruss, A.; Sittinger, M.; Ringe, J. Genome-wide expression profiling reveals new candidate genes associated with osteoarthritis. Osteoarthr. Cartil. 2010, 18, 581-592. [CrossRef] [PubMed] 
104. Shakibaei, M.; John, T.; De Souza, P.; Rahmanzadeh, R.; Merker, H.J. Signal transduction by beta1 integrin receptors in human chondrocytes in vitro: Collaboration with the insulin-like growth factor-I receptor. Biochem. J. 1999, 342 Pt 3, 615-623. [CrossRef]

105. Sitara, D.; Aliprantis, A.O. Transcriptional regulation of bone and joint remodeling by NFAT. Immunol. Rev. 2010, 233, 286-300. [CrossRef]

106. Dolmetsch, R.E.; Lewis, R.S.; Goodnow, C.C.; Healy, J.I. Differential activation of transcription factors induced by Ca2+ response amplitude and duration. Nature 1997, 386, 855-858. [CrossRef]

107. Nishimori, S.; Lai, F.; Shiraishi, M.; Kobayashi, T.; Kozhemyakina, E.; Yao, T.P.; Lassar, A.B.; Kronenberg, H.M. PTHrP targets HDAC4 and HDAC5 to repress chondrocyte hypertrophy. JCI Insight 2019, 4. [CrossRef]

108. Takeda, S.; Bonnamy, J.P.; Owen, M.J.; Ducy, P.; Karsenty, G. Continuous expression of Cbfa1 in nonhypertrophic chondrocytes uncovers its ability to induce hypertrophic chondrocyte differentiation and partially rescues Cbfa1-deficient mice. Genes Dev. 2001, 15, 467-481. [CrossRef]

109. Arnold, M.A.; Kim, Y.; Czubryt, M.P.; Phan, D.; McAnally, J.; Qi, X.; Shelton, J.M.; Richardson, J.A.; Bassel-Duby, R.; Olson, E.N. MEF2C transcription factor controls chondrocyte hypertrophy and bone development. Dev. Cell 2007, 12, 377-389. [CrossRef]

110. Cao, K.; Wei, L.; Zhang, Z.; Guo, L.; Zhang, C.; Li, Y.; Sun, C.; Sun, X.; Wang, S.; Li, P.; et al. Decreased histone deacetylase 4 is associated with human osteoarthritis cartilage degeneration by releasing histone deacetylase 4 inhibition of runt-related transcription factor-2 and increasing osteoarthritis-related genes: A novel mechanism of human osteoarthritis cartilage degeneration. Arthritis Res. Ther. 2014, 16, 491. [CrossRef]

111. Hassan, M.Q.; Tare, R.; Lee, S.H.; Mandeville, M.; Weiner, B.; Montecino, M.; van Wijnen, A.J.; Stein, J.L.; Stein, G.S.; Lian, J.B. HOXA10 controls osteoblastogenesis by directly activating bone regulatory and phenotypic genes. Mol. Cell. Biol. 2007, 27, 3337-3352. [CrossRef]

112. Hassan, M.Q.; Tare, R.S.; Lee, S.H.; Mandeville, M.; Morasso, M.I.; Javed, A.; van Wijnen, A.J.; Stein, J.L.; Stein, G.S.; Lian, J.B. BMP2 commitment to the osteogenic lineage involves activation of Runx2 by DLX3 and a homeodomain transcriptional network. J. Biol. Chem. 2006, 281, 40515-40526. [CrossRef]

113. Liu, T.M.; Lee, E.H. Transcriptional regulatory cascades in Runx2-dependent bone development. Tissue Eng. Part B Rev. 2013, 19, 254-263. [CrossRef] [PubMed]

114. Rushton, M.D.; Reynard, L.N.; Barter, M.J.; Refaie, R.; Rankin, K.S.; Young, D.A.; Loughlin, J. Characterization of the cartilage DNA methylome in knee and hip osteoarthritis. Arthritis Rheumatol. 2014, 66, 2450-2460. [CrossRef] [PubMed]

115. Rice, S.J.; Aubourg, G.; Sorial, A.K.; Almarza, D.; Tselepi, M.; Deehan, D.J.; Reynard, L.N.; Loughlin, J. Identification of a novel, methylation-dependent, RUNX2 regulatory region associated with osteoarthritis risk. Hum. Mol. Genet. 2018, 27, 3464-3474. [CrossRef]

116. Bi, W.; Huang, W.; Whitworth, D.J.; Deng, J.M.; Zhang, Z.; Behringer, R.R.; de Crombrugghe, B. Haploinsufficiency of Sox9 results in defective cartilage primordia and premature skeletal mineralization. Proc. Natl. Acad. Sci. USA 2001, 98, 6698-6703. [CrossRef]

117. Huang, W.; Chung, U.I.; Kronenberg, H.M.; de Crombrugghe, B. The chondrogenic transcription factor Sox 9 is a target of signaling by the parathyroid hormone-related peptide in the growth plate of endochondral bones. Proc. Natl. Acad. Sci. USA 2001, 98, 160-165. [CrossRef] [PubMed]

118. Caron, M.M.; Emans, P.J.; Surtel, D.A.; van der Kraan, P.M.; van Rhijn, L.W.; Welting, T.J. BAPX-1/NKX-3.2 acts as a chondrocyte hypertrophy molecular switch in osteoarthritis. Arthritis Rheumatol. 2015, 67, 2944-2956. [CrossRef]

119. Yamashita, S.; Andoh, M.; Ueno-Kudoh, H.; Sato, T.; Miyaki, S.; Asahara, H. Sox9 directly promotes Bapx1 gene expression to repress Runx2 in chondrocytes. Exp. Cell Res. 2009, 315, 2231-2240. [CrossRef]

120. Provot, S.; Kempf, H.; Murtaugh, L.C.; Chung, U.I.; Kim, D.W.; Chyung, J.; Kronenberg, H.M.; Lassar, A.B. Nkx3.2/Bapx1 acts as a negative regulator of chondrocyte maturation. Development 2006, 133, 651-662. [CrossRef]

121. Magee, C.; Nurminskaya, M.; Faverman, L.; Galera, P.; Linsenmayer, T.F. SP3/SP1 transcription activity regulates specific expression of collagen type X in hypertrophic chondrocytes. J. Biol. Chem. 2005, 280, 25331-25338. [CrossRef] [PubMed]

122. Saito, T.; Fukai, A.; Mabuchi, A.; Ikeda, T.; Yano, F.; Ohba, S.; Nishida, N.; Akune, T.; Yoshimura, N.; Nakagawa, T.; et al. Transcriptional regulation of endochondral ossification by HIF-2alpha during skeletal growth and osteoarthritis development. Nat. Med. 2010, 16, 678-686. [CrossRef] [PubMed] 
123. Gu, J.; Lu, Y.; Li, F.; Qiao, L.; Wang, Q.; Li, N.; Borgia, J.A.; Deng, Y.; Lei, G.; Zheng, Q. Identification and characterization of the novel Col10a1 regulatory mechanism during chondrocyte hypertrophic differentiation. Cell Death Dis. 2014, 5, e1469. [CrossRef] [PubMed]

124. Amano, K.; Densmore, M.; Nishimura, R.; Lanske, B. Indian hedgehog signaling regulates transcription and expression of collagen type X via Runx2/Smads interactions. J. Biol. Chem. 2014, 289, 24898-24910. [CrossRef] [PubMed]

125. Hellingman, C.A.; Davidson, E.N.; Koevoet, W.; Vitters, E.L.; van den Berg, W.B.; van Osch, G.J.; van der Kraan, P.M. Smad signaling determines chondrogenic differentiation of bone-marrow-derived mesenchymal stem cells: Inhibition of Smad1/5/8P prevents terminal differentiation and calcification. Tissue Eng. Part A 2011, 17, 1157-1167. [CrossRef] [PubMed]

126. Lee, K.S.; Hong, S.H.; Bae, S.C. Both the Smad and p38 MAPK pathways play a crucial role in Runx2 expression following induction by transforming growth factor-beta and bone morphogenetic protein. Oncogene 2002, 21, 7156-7163. [CrossRef] [PubMed]

127. He, X.; Ohba, S.; Hojo, H.; McMahon, A.P. AP-1 family members act with Sox9 to promote chondrocyte hypertrophy. Development 2016, 143, 3012-3023. [CrossRef] [PubMed]

128. Yang, S.; Kim, J.; Ryu, J.H.; Oh, H.; Chun, C.H.; Kim, B.J.; Min, B.H.; Chun, J.S. Hypoxia-inducible factor-2alpha is a catabolic regulator of osteoarthritic cartilage destruction. Nat. Med. 2010, 16, 687-693. [CrossRef]

129. Nagase, H.; Nagasawa, Y.; Tachida, Y.; Sakakibara, S.; Okutsu, J.; Suematsu, N.; Arita, S.; Shimada, K. Deiodinase 2 upregulation demonstrated in osteoarthritis patients cartilage causes cartilage destruction in tissue-specific transgenic rats. Osteoarthr. Cartil. 2013, 21, 514-523. [CrossRef] [PubMed]

130. Bomer, N.; den Hollander, W.; Ramos, Y.F.; Bos, S.D.; van der Breggen, R.; Lakenberg, N.; Pepers, B.A.; van Eeden, A.E.; Darvishan, A.; Tobi, E.W.; et al. Underlying molecular mechanisms of DIO2 susceptibility in symptomatic osteoarthritis. Ann. Rheum. Dis. 2015, 74, 1571-1579. [CrossRef] [PubMed]

131. Ionescu, A.; Kozhemyakina, E.; Nicolae, C.; Kaestner, K.H.; Olsen, B.R.; Lassar, A.B. FoxA family members are crucial regulators of the hypertrophic chondrocyte differentiation program. Dev. Cell 2012, 22, 927-939. [CrossRef] [PubMed]

132. Ho, K.; Perez, R.F.; Kim, R.; Xu, L.; Teguh, D.A.; Gamer, L.; Kozhemyakina, E.; Lassar, A.; Li, Y.; Kaestner, K.; et al. The Role of Foxa2 Transcription Factor as Potential Regulator of Articular Cartilage Hypertrophy and Oa Progression. Osteoarthr. Cartil. 2019, 27, S157-S158. [CrossRef]

133. McCulloch, K.; Litherland, G.J.; Rai, T.S. Cellular senescence in osteoarthritis pathology. Aging Cell 2017, 16, 210-218. [CrossRef]

134. Xu, M.; Bradley, E.W.; Weivoda, M.M.; Hwang, S.M.; Pirtskhalava, T.; Decklever, T.; Curran, G.L.; Ogrodnik, M.; Jurk, D.; Johnson, K.O.; et al. Transplanted Senescent Cells Induce an Osteoarthritis-Like Condition in Mice. J. Gerontol. A Biol. Sci. Med. Sci. 2017, 72, 780-785. [CrossRef] [PubMed]

135. Freund, A.; Patil, C.K.; Campisi, J. p38MAPK is a novel DNA damage response-independent regulator of the senescence-associated secretory phenotype. EMBO J. 2011, 30, 1536-1548. [CrossRef]

136. Rose, J.; Soder, S.; Skhirtladze, C.; Schmitz, N.; Gebhard, P.M.; Sesselmann, S.; Aigner, T. DNA damage, discoordinated gene expression and cellular senescence in osteoarthritic chondrocytes. Osteoarthr. Cartil. 2012, 20, 1020-1028. [CrossRef]

137. Ghosh, R.; Mitchell, D.L. Effect of oxidative DNA damage in promoter elements on transcription factor binding. Nucleic Acids Res. 1999, 27, 3213-3218. [CrossRef]

138. Aida, Y.; Maeno, M.; Suzuki, N.; Namba, A.; Motohashi, M.; Matsumoto, M.; Makimura, M.; Matsumura, H. The effect of IL-1beta on the expression of inflammatory cytokines and their receptors in human chondrocytes. Life Sci. 2006, 79, 764-771. [CrossRef]

139. Nagai, K.; Matsushita, T.; Matsuzaki, T.; Takayama, K.; Matsumoto, T.; Kuroda, R.; Kurosaka, M. Depletion of SIRT6 causes cellular senescence, DNA damage, and telomere dysfunction in human chondrocytes. Osteoarthr. Cartil. 2015, 23, 1412-1420. [CrossRef]

140. Wu, Y.; Chen, L.; Wang, Y.; Li, W.; Lin, Y.; Yu, D.; Zhang, L.; Li, F.; Pan, Z. Overexpression of Sirtuin 6 suppresses cellular senescence and NF-kappaB mediated inflammatory responses in osteoarthritis development. Sci. Rep. 2015, 5, 17602. [CrossRef]

141. Kawahara, T.L.; Michishita, E.; Adler, A.S.; Damian, M.; Berber, E.; Lin, M.; McCord, R.A.; Ongaigui, K.C.; Boxer, L.D.; Chang, H.Y.; et al. SIRT6 links histone H3 lysine 9 deacetylation to NF-kappaB-dependent gene expression and organismal life span. Cell 2009, 136, 62-74. [CrossRef] 
142. Wang, R.; Zhang, S.; Previn, R.; Chen, D.; Jin, Y.; Zhou, G. Role of Forkhead Box O Transcription Factors in Oxidative Stress-Induced Chondrocyte Dysfunction: Possible Therapeutic Target for Osteoarthritis? Int. J. Mol. Sci. 2018, 19, 3794. [CrossRef] [PubMed]

143. Akasaki, Y.; Hasegawa, A.; Saito, M.; Asahara, H.; Iwamoto, Y.; Lotz, M.K. Dysregulated FOXO transcription factors in articular cartilage in aging and osteoarthritis. Osteoarthr. Cartil. 2014, 22, 162-170. [CrossRef]

144. Zhao, X.; Huang, P.; Li, G.; Feng, Y.; Zhendong, L.; Zhou, C.; Hu, G.; Xu, Q. Overexpression of Pitx1 attenuates the senescence of chondrocytes from osteoarthritis degeneration cartilage-A self-controlled model for studying the etiology and treatment of osteoarthritis. Bone 2020, 131, 115177. [CrossRef] [PubMed]

145. Kang, C.; Xu, Q.; Martin, T.D.; Li, M.Z.; Demaria, M.; Aron, L.; Lu, T.; Yankner, B.A.; Campisi, J.; Elledge, S.J. The DNA damage response induces inflammation and senescence by inhibiting autophagy of GATA4. Science 2015, 349, aaa5612. [CrossRef] [PubMed]

146. Kang, D.; Shin, J.; Cho, Y.; Kim, H.S.; Gu, Y.R.; Kim, H.; You, K.T.; Chang, M.J.; Chang, C.B.; Kang, S.B.; et al. Stress-activated miR-204 governs senescent phenotypes of chondrocytes to promote osteoarthritis development. Sci. Transl. Med. 2019, 11. [CrossRef]

147. Shirakawa, F.; Saito, K.; Bonagura, C.A.; Galson, D.L.; Fenton, M.J.; Webb, A.C.; Auron, P.E. The human prointerleukin 1 beta gene requires DNA sequences both proximal and distal to the transcription start site for tissue-specific induction. Mol. Cell. Biol. 1993, 13, 1332-1344. [CrossRef]

148. Hashimoto, K.; Otero, M.; Imagawa, K.; de Andres, M.C.; Coico, J.M.; Roach, H.I.; Oreffo, R.O.; Marcu, K.B.; Goldring, M.B. Regulated transcription of human matrix metalloproteinase 13 (MMP13) and interleukin-1beta (IL1B) genes in chondrocytes depends on methylation of specific proximal promoter CpG sites. J. Biol. Chem. 2013, 288, 10061-10072. [CrossRef] [PubMed]

149. Coimbra, I.B.; Jimenez, S.A.; Hawkins, D.F.; Piera-Velazquez, S.; Stokes, D.G. Hypoxia inducible factor-1 alpha expression in human normal and osteoarthritic chondrocytes. Osteoarthr. Cartil. 2004, 12, 336-345. [CrossRef]

150. Salotti, J.; Johnson, P.F. Regulation of senescence and the SASP by the transcription factor C/EBPbeta. Exp. Gerontol. 2019, 128, 110752. [CrossRef]

151. Shimada, H.; Sakakima, H.; Tsuchimochi, K.; Matsuda, F.; Komiya, S.; Goldring, M.B.; Ijiri, K. Senescence of chondrocytes in aging articular cartilage: GADD45beta mediates p21 expression in association with C/EBPbeta in senescence-accelerated mice. Pathol. Res. Pract. 2011, 207, 225-231. [CrossRef] [PubMed]

152. Kang, S.; Jung, M.; Kim, C.W.; Shin, D.Y. Inactivation of p38 kinase delays the onset of senescence in rabbit articular chondrocytes. Mech. Ageing Dev. 2005, 126, 591-597. [CrossRef] [PubMed]

153. Li, Y.S.; Zhang, F.J.; Zeng, C.; Luo, W.; Xiao, W.F.; Gao, S.G.; Lei, G.H. Autophagy in osteoarthritis. Joint Bone Spine 2016, 83, 143-148. [CrossRef] [PubMed]

154. Dikic, I.; Elazar, Z. Mechanism and medical implications of mammalian autophagy. Nat. Rev. Mol. Cell Biol. 2018, 19, 349-364. [CrossRef] [PubMed]

155. Ravanan, P.; Srikumar, I.F.; Talwar, P. Autophagy: The spotlight for cellular stress responses. Life Sci. 2017, 188, 53-67. [CrossRef] [PubMed]

156. Pietrocola, F.; Izzo, V.; Niso-Santano, M.; Vacchelli, E.; Galluzzi, L.; Maiuri, M.C.; Kroemer, G. Regulation of autophagy by stress-responsive transcription factors. Semin. Cancer Biol. 2013, 23, 310-322. [CrossRef]

157. Harris, J.; Hartman, M.; Roche, C.; Zeng, S.G.; O'Shea, A.; Sharp, F.A.; Lambe, E.M.; Creagh, E.M.; Golenbock, D.T.; Tschopp, J.; et al. Autophagy controls IL-1beta secretion by targeting pro-IL-1beta for degradation. J. Biol. Chem. 2011, 286, 9587-9597. [CrossRef]

158. Zhong, Z.; Sanchez-Lopez, E.; Karin, M. Autophagy, NLRP3 inflammasome and auto-inflammatory/immune diseases. Clin. Exp. Rheumatol. 2016, 34, 12-16.

159. Shi, C.S.; Shenderov, K.; Huang, N.N.; Kabat, J.; Abu-Asab, M.; Fitzgerald, K.A.; Sher, A.; Kehrl, J.H. Activation of autophagy by inflammatory signals limits IL-1beta production by targeting ubiquitinated inflammasomes for destruction. Nat. Immunol. 2012, 13, 255-263. [CrossRef]

160. Chen, Z.; Zhong, H.; Wei, J.; Lin, S.; Zong, Z.; Gong, F.; Huang, X.; Sun, J.; Li, P.; Lin, H.; et al. Inhibition of Nrf2/HO-1 signaling leads to increased activation of the NLRP3 inflammasome in osteoarthritis. Arthritis Res. Ther. 2019, 21, 300. [CrossRef]

161. Barbosa, M.C.; Grosso, R.A.; Fader, C.M. Hallmarks of Aging: An Autophagic Perspective. Front. Endocrinol. (Lausanne) 2018, 9, 790. [CrossRef] [PubMed] 
162. Sasaki, H.; Takayama, K.; Matsushita, T.; Ishida, K.; Kubo, S.; Matsumoto, T.; Fujita, N.; Oka, S.; Kurosaka, M.; Kuroda, R. Autophagy modulates osteoarthritis-related gene expression in human chondrocytes. Arthritis Rheum. 2012, 64, 1920-1928. [CrossRef] [PubMed]

163. Takayama, K.; Kawakami, Y.; Kobayashi, M.; Greco, N.; Cummins, J.H.; Matsushita, T.; Kuroda, R.; Kurosaka, M.; Fu, F.H.; Huard, J. Local intra-articular injection of rapamycin delays articular cartilage degeneration in a murine model of osteoarthritis. Arthritis Res. Ther. 2014, 16, 482. [CrossRef] [PubMed]

164. Cheng, N.T.; Meng, H.; Ma, L.F.; Zhang, L.; Yu, H.M.; Wang, Z.Z.; Guo, A. Role of autophagy in the progression of osteoarthritis: The autophagy inhibitor, 3-methyladenine, aggravates the severity of experimental osteoarthritis. Int. J. Mol. Med. 2017, 39, 1224-1232. [CrossRef] [PubMed]

165. Parzych, K.R.; Klionsky, D.J. An overview of autophagy: Morphology, mechanism, and regulation. Antioxid. Redox Signal. 2014, 20, 460-473. [CrossRef]

166. Sakamaki, J.I.; Wilkinson, S.; Hahn, M.; Tasdemir, N.; O’Prey, J.; Clark, W.; Hedley, A.; Nixon, C.; Long, J.S.; New, M.; et al. Bromodomain Protein BRD4 Is a Transcriptional Repressor of Autophagy and Lysosomal Function. Mol. Cell 2017, 66, 517-532. [CrossRef]

167. Jiang, Y.; Zhu, L.; Zhang, T.; Lu, H.; Wang, C.; Xue, B.; Xu, X.; Liu, Y.; Cai, Z.; Sang, W.; et al. BRD4 has dual effects on the HMGB1 and NF-kappaB signalling pathways and is a potential therapeutic target for osteoarthritis. Biochim. Biophys. Acta Mol. Basis. Dis. 2017, 1863, 3001-3015. [CrossRef]

168. Hong, J.; Li, S.; Markova, D.Z.; Liang, A.; Kepler, C.K.; Huang, Y.; Zhou, J.; Yan, J.; Chen, W.; Huang, D.; et al. Bromodomain-containing protein 4 inhibition alleviates matrix degradation by enhancing autophagy and suppressing NLRP3 inflammasome activity in NP cells. J. Cell. Physiol. 2020, 235, 5736-5749. [CrossRef]

169. Liao, F.X.; Huang, F.; Ma, W.G.; Qin, K.P.; Xu, P.F.; Wu, Y.F.; Wang, H.; Chang, J.; Yin, Z.S. The New Role of Sirtuin1 in Human Osteoarthritis Chondrocytes by Regulating Autophagy. Cartilage 2019, 1947603519847736. [CrossRef]

170. Sacitharan, P.K.; Bou-Gharios, G.; Edwards, J.R. SIRT1 directly activates autophagy in human chondrocytes. Cell Death Discov. 2020, 6, 41. [CrossRef]

171. Brunet, A.; Sweeney, L.B.; Sturgill, J.F.; Chua, K.F.; Greer, P.L.; Lin, Y.; Tran, H.; Ross, S.E.; Mostoslavsky, R.; Cohen, H.Y.; et al. Stress-dependent regulation of FOXO transcription factors by the SIRT1 deacetylase. Science 2004, 303, 2011-2015. [CrossRef] [PubMed]

172. Settembre, C.; Di Malta, C.; Polito, V.A.; Garcia Arencibia, M.; Vetrini, F.; Erdin, S.; Erdin, S.U.; Huynh, T.; Medina, D.; Colella, P.; et al. TFEB links autophagy to lysosomal biogenesis. Science 2011, 332, 1429-1433. [CrossRef] [PubMed]

173. Chauhan, S.; Goodwin, J.G.; Chauhan, S.; Manyam, G.; Wang, J.; Kamat, A.M.; Boyd, D.D. ZKSCAN3 is a master transcriptional repressor of autophagy. Mol. Cell 2013, 50, 16-28. [CrossRef]

174. Zheng, G.; Zhan, Y.; Li, X.; Pan, Z.; Zheng, F.; Zhang, Z.; Zhou, Y.; Wu, Y.; Wang, X.; Gao, W.; et al. TFEB, a potential therapeutic target for osteoarthritis via autophagy regulation. Cell Death Dis. 2018, 9, 858. [CrossRef]

175. Martina, J.A.; Chen, Y.; Gucek, M.; Puertollano, R. MTORC1 functions as a transcriptional regulator of autophagy by preventing nuclear transport of TFEB. Autophagy 2012, 8, 903-914. [CrossRef] [PubMed]

176. Zhang, Y.; Vasheghani, F.; Li, Y.H.; Blati, M.; Simeone, K.; Fahmi, H.; Lussier, B.; Roughley, P.; Lagares, D.; Pelletier, J.P.; et al. Cartilage-specific deletion of mTOR upregulates autophagy and protects mice from osteoarthritis. Ann. Rheum. Dis. 2015, 74, 1432-1440. [CrossRef]

177. Zhang, H.; Wang, H.; Zeng, C.; Yan, B.; Ouyang, J.; Liu, X.; Sun, Q.; Zhao, C.; Fang, H.; Pan, J.; et al. mTORC1 activation downregulates FGFR3 and PTH/PTHrP receptor in articular chondrocytes to initiate osteoarthritis. Osteoarthr. Cartil. 2017, 25, 952-963. [CrossRef]

178. Akasaki, Y.; Alvarez-Garcia, O.; Saito, M.; Carames, B.; Iwamoto, Y.; Lotz, M.K. FoxO transcription factors support oxidative stress resistance in human chondrocytes. Arthritis Rheumatol. 2014, 66, 3349-3358. [CrossRef]

179. Matsuzaki, T.; Alvarez-Garcia, O.; Mokuda, S.; Nagira, K.; Olmer, M.; Gamini, R.; Miyata, K.; Akasaki, Y.; $\mathrm{Su}$, A.I.; Asahara, H.; et al. FoxO transcription factors modulate autophagy and proteoglycan 4 in cartilage homeostasis and osteoarthritis. Sci. Transl. Med. 2018, 10. [CrossRef]

180. Xie, J.; Lin, J.; Wei, M.; Teng, Y.; He, Q.; Yang, G.; Yang, X. Sustained Akt signaling in articular chondrocytes causes osteoarthritis via oxidative stress-induced senescence in mice. Bone Res. 2019, 7, 23. [CrossRef] 
181. Van Spil, W.E.; Kubassova, O.; Boesen, M.; Bay-Jensen, A.C.; Mobasheri, A. Osteoarthritis phenotypes and novel therapeutic targets. Biochem. Pharmacol. 2019, 165, 41-48. [CrossRef] [PubMed]

182. Vaquerizas, J.M.; Kummerfeld, S.K.; Teichmann, S.A.; Luscombe, N.M. A census of human transcription factors: Function, expression and evolution. Nat. Rev. Genet. 2009, 10, 252-263. [CrossRef] [PubMed]

183. Lambert, M.; Jambon, S.; Depauw, S.; David-Cordonnier, M.H. Targeting Transcription Factors for Cancer Treatment. Molecules 2018, 23, 1479. [CrossRef] [PubMed]

184. de Launoit, Y.; Baert, J.L.; Chotteau-Lelievre, A.; Monte, D.; Coutte, L.; Mauen, S.; Firlej, V.; Degerny, C.; Verreman, K. The Ets transcription factors of the PEA3 group: Transcriptional regulators in metastasis. Biochim. Biophys. Acta 2006, 1766, 79-87. [CrossRef] [PubMed]

185. Rahim, S.; Beauchamp, E.M.; Kong, Y.; Brown, M.L.; Toretsky, J.A.; Uren, A. YK-4-279 inhibits ERG and ETV1 mediated prostate cancer cell invasion. PLoS ONE 2011, 6, e19343. [CrossRef]

186. Dai, J.; Punchihewa, C.; Mistry, P.; Ooi, A.T.; Yang, D. Novel DNA bis-intercalation by MLN944, a potent clinical bisphenazine anticancer drug. J. Biol. Chem. 2004, 279, 46096-46103. [CrossRef]

187. Hecker, M.; Wagner, A.H. Transcription factor decoy technology: A therapeutic update. Biochem. Pharmacol. 2017, 144, 29-34. [CrossRef]

188. Miyake, T.; Miyake, T.; Sakaguchi, M.; Nankai, H.; Nakazawa, T.; Morishita, R. Prevention of Asthma Exacerbation in a Mouse Model by Simultaneous Inhibition of NF-kappaB and STAT6 Activation Using a Chimeric Decoy Strategy. Mol. Ther. Nucleic Acids 2018, 10, 159-169. [CrossRef]

189. Moiseeva, O.; Deschenes-Simard, X.; St-Germain, E.; Igelmann, S.; Huot, G.; Cadar, A.E.; Bourdeau, V.; Pollak, M.N.; Ferbeyre, G. Metformin inhibits the senescence-associated secretory phenotype by interfering with IKK/NF-kappaB activation. Aging Cell 2013, 12, 489-498. [CrossRef]

190. Lee, S.Y.; Lee, S.H.; Na, H.S.; Kwon, J.Y.; Kim, G.Y.; Jung, K.; Cho, K.H.; Kim, S.A.; Go, E.J.; Park, M.J.; et al. The Therapeutic Effect of STAT3 Signaling-Suppressed MSC on Pain and Articular Cartilage Damage in a Rat Model of Monosodium Iodoacetate-Induced Osteoarthritis. Front. Immunol. 2018, 9, 2881. [CrossRef]

191. Ouyang, Y.; Wang, W.; Tu, B.; Zhu, Y.; Fan, C.; Li, Y. Overexpression of SOX9 alleviates the progression of human osteoarthritis in vitro and in vivo. Drug Des. Dev. Ther. 2019, 13, 2833-2842. [CrossRef] [PubMed]

192. Aini, H.; Itaka, K.; Fujisawa, A.; Uchida, H.; Uchida, S.; Fukushima, S.; Kataoka, K.; Saito, T.; Chung, U.I.; Ohba, S. Messenger RNA delivery of a cartilage-anabolic transcription factor as a disease-modifying strategy for osteoarthritis treatment. Sci. Rep. 2016, 6, 18743. [CrossRef] [PubMed]

193. Iachettini, S.; Trisciuoglio, D.; Rotili, D.; Lucidi, A.; Salvati, E.; Zizza, P.; Di Leo, L.; Del Bufalo, D.; Ciriolo, M.R.; Leonetti, C.; et al. Pharmacological activation of SIRT6 triggers lethal autophagy in human cancer cells. Cell Death Dis. 2018, 9, 996. [CrossRef] [PubMed]

194. Zhi, L.Q.; Yao, S.X.; Liu, H.L.; Li, M.; Duan, N.; Ma, J.B. Hydroxytyrosol inhibits the inflammatory response of osteoarthritis chondrocytes via SIRT6-mediated autophagy. Mol. Med. Rep. 2018, 17, 4035-4042. [CrossRef] [PubMed]

195. Cusanovich, D.A.; Pavlovic, B.; Pritchard, J.K.; Gilad, Y. The functional consequences of variation in transcription factor binding. PLoS Genet. 2014, 10, e1004226. [CrossRef]

196. Wei, N.; Li, J.; Fang, C.; Chang, J.; Xirou, V.; Syrigos, N.K.; Marks, B.J.; Chu, E.; Schmitz, J.C. Targeting colon cancer with the novel STAT3 inhibitor bruceantinol. Oncogene 2019, 38, 1676-1687. [CrossRef]

197. Shang, Y.; Brown, M. Molecular determinants for the tissue specificity of SERMs. Science 2002, 295, $2465-2468$. [CrossRef]

198. Davies, C.; Pan, H.; Godwin, J.; Gray, R.; Arriagada, R.; Raina, V.; Abraham, M.; Medeiros Alencar, V.H.; Badran, A.; Bonfill, X.; et al. Long-term effects of continuing adjuvant tamoxifen to 10 years versus stopping at 5 years after diagnosis of oestrogen receptor-positive breast cancer: ATLAS, a randomised trial. Lancet 2013, 381, 805-816. [CrossRef]

199. Bushweller, J.H. Targeting transcription factors in cancer-From undruggable to reality. Nat. Rev. Cancer 2019, 19, 611-624. [CrossRef]

200. Kavanaugh, T.E.; Werfel, T.A.; Cho, H.; Hasty, K.A.; Duvall, C.L. Particle-based technologies for osteoarthritis detection and therapy. Drug Deliv. Transl. Res. 2016, 6, 132-147. [CrossRef]

201. Eymard, F.; Chevalier, X. Pharmacological treatments of knee osteoarthritis. Rev. Prat. 2019, 69, 515-519. [PubMed] 
202. Bottini, M.; Bhattacharya, K.; Fadeel, B.; Magrini, A.; Bottini, N.; Rosato, N. Nanodrugs to target articular cartilage: An emerging platform for osteoarthritis therapy. Nanomedicine 2016, 12, 255-268. [CrossRef] [PubMed]

203. Geiger, B.C.; Wang, S.; Padera, R.F., Jr.; Grodzinsky, A.J.; Hammond, P.T. Cartilage-penetrating nanocarriers improve delivery and efficacy of growth factor treatment of osteoarthritis. Sci. Transl. Med. 2018, 10. [CrossRef] [PubMed]

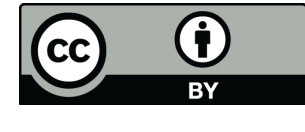

(C) 2020 by the authors. Licensee MDPI, Basel, Switzerland. This article is an open access article distributed under the terms and conditions of the Creative Commons Attribution (CC BY) license (http://creativecommons.org/licenses/by/4.0/). 